\title{
Elongated TCR alpha chain CDR3 favors an altered CD4 cytokine profile
}

\author{
Catherine Reynolds ${ }^{1}$, Deborah Chong ${ }^{1}$, Eleanor Raynsford ${ }^{1}$, Kathryn Quigley', Deborah Kelly', \\ Julia Llewellyn-Hughes ${ }^{2}$, Daniel Altmann ${ }^{1}$ and Rosemary Boyton ${ }^{1 *}$
}

\begin{abstract}
Background: CD4 T lymphocyte activation requires T cell receptor (TCR) engagement by peptide/MHC (major histocompatibility complex) (pMHC). The TCR complementarity-determining region 3 (CDR3) contains variable a and $\beta$ loops critical for $\mathrm{pMHC}$ recognition. During any immune response, tuning of TCR usage through progressive clonal selection occurs. Th1 and Th2 cells operate at different avidities for activation and display distinct transcriptional programs, although polarization may be plastic, influenced by pathogens and cytokines. We therefore hypothesized that CDR3aß sequence features may intrinsically influence CD4 phenotype during progression of a response.

Results: We show that CD4 polarization involves distinct CDR3a usage: Th1 and Th17 cells favored short TCR CDR3a sequences of 12 and 11 amino acids, respectively, while Th2 cells favored elongated CDR3a loops of 14 amino acids, with lower predicted affinity. The dominant Th2- and Th1-derived TCRa sequences with14 amino acid CDR3 loops and 12 amino acid CDR3 loops, respectively, were expressed in TCR transgenics. The functional impact of these TCRa transgenes was assessed after in vivo priming with a peptide/adjuvant. The short, Th1-derived receptor transgenic T cell lines made IFNY, but not IL-4, 5 or 13, while the elongated, Th2-derived receptor transgenic T cell lines made little or no IFNY, but increased IL-4, 5 and 13 with progressive re-stimulations, mirrored by GATA-3 up-regulation. T cells from primed Th2 TCRa transgenics selected dominant TCR V $\beta$ expansions, allowing us to generate TCRa $\beta$ transgenics carrying the favored, Th2-derived receptor heterodimer. Primed T cells from TCRa $\beta$ transgenics made little or no IL-17 or IFNY, but favored IL-9 after priming with Complete Freund's adjuvant and IL-4, 5, 9, 10 and 13 after priming with incomplete Freund's. In tetramer-binding studies, this transgenic receptor showed low binding avidity for pMHC and polarized T cell lines show TCR avidity for Th17 > Th1 > Th2. While transgenic expression of a Th2-derived, 'elongated' TCR-CDR3a and the TCRaß pair, clearly generated a program shifted away from Th1 immunity and with low binding avidity, cytokine-skewing could be over-ridden by altering peptide challenge dose.
\end{abstract}

Conclusion: We propose that selection from responding clones with distinctive TCRs on the basis of functional avidity can direct a preference away from Th1 effector responses, favoring Th2 cytokines.

Keywords: CD4 T cell, T cell receptor, Cytokine, Transgenic, Mouse, Th17, Th1, Th2

\section{Background}

In CD4 immunity, different contexts of antigen recognition, whether in the 'natural setting' of disease or the experimental setting of antigen-priming adjuvant regimens, favor the preferential development of effector populations that belong primarily to Th1, Th2 or Th17 subsets [1,2]. In diseases such as allergic asthma, there is strong, local

\footnotetext{
* Correspondence: r.boyton@imperial.ac.uk

'Lung Immunology Group, Infectious Diseases and Immunity, Department of Medicine, Imperial College, Hammersmith Hospital, Du Cane Road, London W12 ONN, UK

Full list of author information is available at the end of the article
}

Th2 immunity, while influenza infection induces a Th1 profile $[3,4]$. There are several mechanisms driving CD4 T cells into these alternate differentiation fates, including the local cytokine milieu. This partly reflects the experimental designs most accessible for reductionist models (that is, adding recombinant cytokines to purified, naïve cells to track polarization). However, it has relevance extending to the mechanisms involved in natural infection. Dendritic cell (DC) programming through IL-12 or IL-18 leading to Th1-polarization is commonly modeled by Toll-like receptor (TLR) agonism with bacterial products, the prototypic example being TLR agonism by bacterial 
lipopolysaccharide [5]. The nature of stimuli driving a Th2 environment is less clear. IL-10 and IL-4 are candidates for the promotion of an innate Th2-priming environment. However, IL-10 or IL-4 knockout DC can drive Th2 responses [6]. Clues as to the supply of a pro-Th2 DC program have come from looking at Th2-associated pathogen responses. Schistosome egg antigen (SEA), which induces a robust Th2 program in DC, capable even of overriding bacterial Th1 signals [7], depends on a relatively nonactivated transcription profile in the DC, somewhat reminiscent of a tolerogenic profile [8]. This is in keeping with the view that activation of Th2 cells may encompass reduced $\mathrm{T}$ cell receptor (TCR) avidity and/or co-stimulation and altered signaling, synapse formation and off-rates.

Several lines of evidence suggest that Th2 activation has different avidity requirements for Th1 activation. A basic precept is that the TCR reads different potencies of activation to initiate different effector outcomes with the 'strength of stimulation' required for a Th1 response greater than for a Th2 response [9]. Furthermore, more sustained engagement of the TCR by $\mathrm{pMHC}$ is required to polarize TCR transgenic lymphocytes into a Th2 program [10]. The serial triggering model of T-cell activation offers an explanation for these observations; since any given pMHC complex must activate several receptors for cell triggering, the affinity of the interaction must be low and/ or the off-rate fast to enable disengagement to occur and the more sustained the necessary interaction, the greater this will be the case [11]. There are many studies on the relative dose of antigen required for a Th1 or Th2 response; a common observation is that Th1 responses require relatively high concentrations, and Th2 responses much lower [12]. Possible mechanisms for a relationship between antigen dose and $\mathrm{T}$ cell polarization may be both through a direct effect on differential CD3 signaling [13] and through the ability to modulate expression of co-stimulatory molecules expressed by CD4 cells; high antigen dose can favor Th1 development through dosedependent up-regulation of CD40L [14]. Indeed, it has been argued that $\mathrm{Ca}_{2}{ }^{+}$signaling may be reduced in Th2 response and that the threshold interaction necessary for inducing $\mathrm{Ca}^{+}$signaling may not be reached by Th2 cells [15].

In several models, pMHC complexes showing reduced affinity interactions with TCR are associated with preferential skewing to a Th2 response. T cells specific for proteolipoprotein (PLP) 131-159 and selected under Th2favoring conditions show a shift in peptide-TCR primary contact residues compared with Th1 clones [16].

While avidity maturation on a per-cell basis is a property of the $\mathrm{B}$ cell and not the $\mathrm{T}$ cell repertoire, $\mathrm{T}$ cell clonal selection leads to the progressive appearance of selective TCR usage [17-19]. For example, the repertoire of TCR response to sperm whale myoglobulin 110-124 in adjuvant is initially diverse, then progressively losing lower affinity clones and resulting in an oligoclonal population of TCR $\beta$ receptors of intermediate affinity [18]. Similarly, pigeon cytochrome c peptide specific TCR $\beta$ chains show strong selection for CDR3 length and residues characteristic of antigen binding, compatible with progressive clonal maturation and the suggestion of population-level affinity maturation [19]. Repertoire maturation in development of the CD8 response to Listeria involves narrowing of the TCR repertoire, associated with increased affinity [17].

Knowing that development of a response involves selective fine-tuning from available receptors and that avidity requirements differ for activation of different Th subsets, it would be expected that they might selectively expand different TCR repertoires. We previously showed that selection of favored TCRs from the peptide-specific pool differs under Th1 or Th2 conditions [20]. When an initial, mixed pool of primed cells was divided into Th1 or Th2 polarized cultures, different TCR sequences were preferentially selected under the two conditions. Across different $\mathrm{pMHC}$ combinations, there was no clear pattern or homogeneity evident in the selection for TCR $\beta$ usage, but Th2 conditions preferentially selected elongated CDR3 $\alpha$ sequences. The example of the response to PLP $56-70 / \mathrm{H}-2 \mathrm{~A}^{\mathrm{g} 7}$ was studied in detail. Screening of polarized Th line libraries suggested that while Th2 cultures favored these elongated CDR3 $\alpha$ loops but also encompassed receptors with shorter loops, the long loops could never be found in Th1 cultures. Molecular modeling offered a potential explanation, predicting a bulky, obstructive interaction of reduced affinity for the elongated Th2 receptors. Thus, contrary to experiments with the DO11.10 TCR transgenic mouse, whereby a Th1-derived TCR can be skewed to mediate either Th1 or Th2 effector functions [21], in a physiological polarizing environment, receptor features may be preferentially selected so as to skew the future memory response for an appropriate cytokine profile [22]. While it had been envisaged that the cytokine program was faithfully transmitted to progeny cells by chromatin remodeling, polarization is now perceived as a plastic event [2,23-28]. In this context, there may be evolutionary advantage in building information on the appropriate response into the TCR itself, so that the response cannot be diverted to a pathogen-inappropriate response by the local inflammatory environment.

We here investigate this hypothesis by generating TCR transgenics carrying an elongated CDR3, Th2-derived TCR $\alpha$ chain. We show that cells carrying this receptor, particularly when paired with the appropriate TCR $\beta$ partner, facilitate cytokine skewing away from a Th1 program. This is the first time to our knowledge that a causal link between TCR repertoire maturation and Th effector polarization has been shown. The findings suggest that the program for recall of a context-appropriate 
phenotype may be influenced not just by heritable epigenetic changes, but also in the choice of dominant TCRs themselves.

\section{Results}

TCR usage and co-stimulatory molecule expression in polarized CD4 $\mathrm{T}$ cell lines

We previously described the relatively homogeneous TCR $\alpha$ usage associated with a polarized Th2 response to PLP 56 to $70[20,22]$. A noteworthy feature of this TCR usage was the choice of CDR3 $\alpha$ loops that were elongated, an observation extended across several different pMHC combinations, suggesting that the Th2 cytokine environment had influenced preferential utilization of TCRs with these structural features. In order to establish the impact on cytokine polarization of Th2-derived receptors with these features, TCR $\alpha$ chain transgenic lines expressing a representative, elongated CDR3 $\alpha$ receptor were generated. In order to select such a TCR sequence, we sequenced TCR $\alpha$ and $\beta$ chains from polarized Th lines specific for this pMHC combination (H2-A $\mathrm{A}^{\mathrm{g} 7} / \mathrm{PLP} 56$ to 70 ). Primed lymph node cells (LNC) from mice primed with peptide in Complete Freund's adjuvant (CFA) were split into cultures stimulated with antigen in vitro under polarizing Th1, Th2 or Th17 conditions. To generate Th1 lines, cells were cultured in medium containing IL-2, IL-12 and antiIL-4. To generate Th2 lines, cells were cultured in medium containing IL-2, IL-4 and anti-IFNy. For Th17 lines, cells were initially cultured in anti-IFN $\gamma$, anti-IL-4, IL-6 and TGF $\beta$ and expanded in medium containing IL- 2 and IL-23. Each set of conditions yielded a repertoire of TCRs with reproducibly distinct features (Tables 1, 2, 3). In each case, the distinctive CDR3s were a characteristic of the TCR $\alpha$ and not the TCR $\beta$ repertoire. Under Th1 conditions, cultures predominantly favored a Va15J $\alpha 10$ (TRAV10D TRAJ58) receptor with a 12 amino acid CDR3 $\alpha$, AASREGTGSKLS. We never found this receptor or ones similar to it in cultures derived from the same LNC pool but polarized under Th2 or Th17 conditions. Cells cultured under Th2 polarizing conditions favored very different TCR $\alpha$ usage, a quarter of the sequences comprising a V $\alpha 9$ J $\alpha 42$ (TRAV17 TRAJ50) receptor with an elongated, 14-amino acid CDR3 $\alpha$ loop, ALEGIASSSFSKLV. This was not accompanied by any overt selection for dominant TCR $\beta$ chains. Interestingly, cells cultured under Th17 polarizing conditions were also distinctive, a large pro-

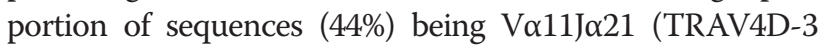
TRAJ27) comprising a short, 11 amino acid CDR3 $\alpha$ loop (AAANTNTGKLT). Again, there was no preferred, expanded TCR $\beta$ chain. The findings suggested selection from the available pool primarily on the basis of TCR $\alpha$ sequence and permissible pairing of dominant TCR $\alpha$ chains with multiple possible $\beta$ chain partners. The Th17 cells were similar to Th1-polarized cultures in being limited to short CDR3 $\alpha$ loops. There was no significant difference in TCR $\beta$ chain CDR3 length seen in Th1 $(12.3 \pm 0.2)$, Th2 $(12.3 \pm 0.2)$ and Th17 $(12.7 \pm 0.2)$ TCR sequences. However, TCR $\alpha$ chain CDR3 lengths were significantly longer in Th2 $(12.2 \pm 0.2)$ than in Th1 $(11.4 \pm 0.1)$ and Th17 $(11.1 \pm 0.1)$ TCR sequences $(P<0.0009)$.

When assayed for release of IFN $\gamma$, IL-4, IL-5, IL-9, IL-13, IL-10 and IL-17, each of the polarized lines showed the expected profiles (Figure 1A). A caveat here is that, in line with observations from others using in vitro and in vivo models, T cells within Th17 cultures could flip relatively easily into co-expression of IL-17 and IFNY [24-27] or single expression of IFNy, (Additional file 1) particularly if derived from an ex-vivo inflammatory environment.

In line with the idea that selection from the initial pool under Th polarizing conditions acts through selection of clones with differing avidities, Th1 and Th2 lines developed with markedly differing profiles of co-stimulatory molecule expression (Figure 1B-F). Th1 lines show greater expression of CD40L, in line with the idea that CD40Lblockade preferentially blocks Th1 responses (Figure 1E) [14]. Expression of OX40, Intercellular adhesion molecule-1 (ICAM-1) and CD5 were also greater on Th1 lines (Figure 1B-D). Conversely, Th2 inducible T-cell co-stimulator (ICOS) expression was greater, as predicted by the finding that ICOS stimulation preferentially triggers Th2 cytokines (Figure 1F) [28]. The CD5 expression differences are reminiscent of observations in a recent paper by Mandl and colleagues, who showed that TCR transgenic

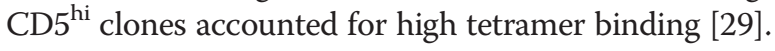

\section{Generation of TCRVa chain transgenics}

We expressed the immunodominant selected TCR $\alpha$ sequence (V $\alpha$ 9J $\alpha 42$ (TRAV17 TRAJ50) receptor with an elongated, 14-amino acid CDR3 $\alpha$ loop, ALEGIASSSFSKLV) in the pT $\alpha$ expression cassette, and made two independent transgenic founder lines expressing the dominant Th2-derived TCR $\alpha$ chain with an elongated CDR3 region (line 20 and line 34). We expressed the immunodominant selected TCR $\alpha$ sequence (V $\alpha 15$ J $\alpha 10$ (TRAV10D TRAJ58) receptor with a 12 -amino acid CDR3 $\alpha$, AASREGTGSKLS) in the pT $\alpha$ expression cassette, and made one transgenic founder line with the dominant Th1-derived TCR $\alpha$ chain with a shorter CDR3 region (line 30). All the transgenic lines were then backcrossed onto the original non-obese diabetic, H2-E transgenic (NOD.E) background in which the $\mathrm{T}$ cells had been characterized (Figure 2A, B).

\section{Transgenic expression of TCRVa chain with an elongated CDR3 does not favor Th1 responses in primed cells}

With respect to TCR selection in Th2 T cell lines, the absence of any dominant TCR $\beta$ chain in cultures led us to hypothesize that transgenic expression of the TCR $\alpha$ chain with an elongated CDR3 region alone might be 
Table 1 TCR $a$ and $\beta$ chain repertoires of a Th1 polarized T cell line

\begin{tabular}{|c|c|c|c|c|c|}
\hline & & CDR3 region & & CDR3 length & $\%$ \\
\hline \multirow[t]{11}{*}{ TCR alpha } & EDSAIYFC & AASREGTGSKLS & FGKG & 12 & 34 \\
\hline & SDSAKYFC & ALEGRGGRALI & FGTG & 11 & 20 \\
\hline & EDSGTYFC & AALPGTGSNRLT & FGKG & 12 & 18 \\
\hline & GDSAMYFC & AAKNSGTYQR & FGTG & 10 & 8 \\
\hline & GDSAIYFC & SASMTNNNNRIF & FGDG & 12 & 6 \\
\hline & EDSGTYFC & AADSNYQLI & WGSG & 9 & 4 \\
\hline & EDSGTYFC & AAETNSAGNKLT & FGIG & 12 & 2 \\
\hline & EDSGTYFC & AADSNHQLI & FGSG & 9 & 2 \\
\hline & EDSGTYFC & AAEAANYNVLY & FGSG & 11 & 2 \\
\hline & EDSAIYFC & AASKPNNRIF & FGDG & 10 & 2 \\
\hline & SDSAVYFC & ALSALGTGNYKYV & FGAG & 13 & 2 \\
\hline \multirow[t]{20}{*}{ TCR beta } & DDSATYFC & ASSQGPLSNERLF & $\mathrm{FGHG}$ & 13 & 22 \\
\hline & NEMAVLFC & ASSRSGDQDTQY & FGPG & 12 & 18 \\
\hline & EDSAVYLC & ASSRDWGDTQY & FGPG & 11 & 14 \\
\hline & DDSATYFC & ASSQEMQGQDTQY & FGPG & 13 & 6 \\
\hline & EDSAVYLC & ASSPWGVQDTQY & FGPG & 12 & 4 \\
\hline & QDSAVYLC & ASSLAGQGARSQNTLY & FGAG & 16 & 4 \\
\hline & SQTSLYFC & ASSPGSNERLF & FGHG & 11 & 4 \\
\hline & KDSAVYLC & ASSLVGAEQF & FGPG & 10 & 4 \\
\hline & DDSATYFC & ASSKAGTGEDTQY & FGPG & 13 & 2 \\
\hline & DDSATYFC & ASSQQGDQDTQY & FGPG & 12 & 2 \\
\hline & DDSATYFC & ASSQEGTGVQDTQY & FGPG & 14 & 2 \\
\hline & DDSATYFC & ASSQEGTGGDEQY & FGPG & 13 & 2 \\
\hline & DDSATYFC & ASSQEGLSSYEQY & FGPG & 13 & 2 \\
\hline & DDSATYFC & ASSQEGLGNYEQY & FGPG & 13 & 2 \\
\hline & DDSATYFC & ASSQEMQGDQDTQY & FGPG & 14 & 2 \\
\hline & QDSAVYLC & ASSNQNYAEQF & FGPG & 11 & 2 \\
\hline & QDSAVYLC & ASSSRDWGDEQY & FGPG & 12 & 2 \\
\hline & EDSAVYFC & ASSQAGTDTQY & FGPG & 11 & 2 \\
\hline & EDSAVYFC & ASSSPGGSYEQY & FGPG & 12 & 2 \\
\hline & SQTSVYFC & ASGDSQGANQAPL & FGEG & 13 & 2 \\
\hline
\end{tabular}

T cell lines were maintained in culture for one round of re-stimulation under highly polarizing conditions before taking RNA for TCR sequence analysis. TCRa and $\beta$ chain repertoire analysis of an $\mathrm{H} 2-\mathrm{A}^{97} / \mathrm{PLP} 56-70$ specific Th1, Th2 and Th17 cell lines shows expansion of distinct, dominant TCRa chains in the absence of a dominant $\beta$ chain. The frequency (\%) of each unique TCR sequence identified is shown. CDR3 length is defined as the number of amino acids between the invariant $C$ residue and the F/W-G-X-G motif. TCRa and TCR $\beta$ CDR3 region lengths are shown in each table. Data are representative of 50 TCRa and 50 TCR $\beta$ sequences for each T cell line. The mean CDR3 length for the TCRa chain is $12.2 \pm 0.2$ (SE) for Th2 cultures, $11.4 \pm 0.1$ (SE) for Th1 cultures, and $11.1 \pm 0.1$ (SE) for Th17 cultures.

The most dominant TCR alpha sequence is shown in bold.

Mean CDR3a length $11.42+0.13(\mathrm{SE})(n=50)$.

Mean CDR3 $\beta$ length $12.30+0.17$ (SE) $(n=50)$.

sufficient to impact on cytokine phenotype of the $\mathrm{T}$ cell response.

We initially assessed the functional impact of the elongated TCR $\alpha$ chain on $\mathrm{CD}^{+}{ }^{+} \mathrm{T}$ cell responses by immunizing mice to look both at initial recall responses and subsequently after a second antigen boost in vivo (Figure 3 ). The nature of ex-vivo cytokine responses is heavily influenced by the adjuvants used for priming, with CFA giving strong Th1 polarization through the effect of $M$. tuberculosis on MyD88-dependent signaling [30]. We, therefore, assessed whether this TCR could confer propensity to develop a Th2 program in the face of a Th1skewing, CFA priming regimen. Mice were immunized on Day 0 and Day 28 with PLP 56 to 70 in CFA and incomplete Freund's adjuvant (IFA), respectively, and T cell responses sampled at days 10, 28 and 32. At each timepoint, $\mathrm{T}$ cell responses of TCR $\alpha$ chain transgenics were similar to littermate controls as judged by proliferation 
Table 2 TCRa and $\beta$ chain repertoires of a Th2 polarized T cell line

\begin{tabular}{|c|c|c|c|c|c|}
\hline & & CDR3 region & & CDR3 length & $\%$ \\
\hline \multirow[t]{13}{*}{ TCR alpha } & SDSAKYFC & ALEGIASSSFSKLV & FGQG & 14 & 24 \\
\hline & GDSAAYFC & AVRGTNAYKVI & FGKG & 11 & 16 \\
\hline & SDSALYYC & ALSDANNYAQGLT & FGLG & 13 & 14 \\
\hline & GDSAAYFC & AAGDTNTGKLT & FGDG & 11 & 10 \\
\hline & EDSAIYFC & AASRGNMGYKLT & FGTG & 12 & 8 \\
\hline & GDSAAYFC & AALNTNTGELT & FGDG & 11 & 6 \\
\hline & SDSAVYYC & ALVRDTGYQNFY & FGKG & 12 & 4 \\
\hline & SDSAVYYC & ALGEDTNAYKVI & FGKG & 12 & 4 \\
\hline & SDSAVYYC & ALGFQGGRALI & FGTG & 11 & 4 \\
\hline & GDSAMYFC & AAPPMNYNQGKLI & FGOG & 13 & 4 \\
\hline & TDSGTYFC & AMERODNYAOGLT & FGLG & 13 & 2 \\
\hline & EDSGTYFC & AADNRIF & FGDG & 31 & 2 \\
\hline & SDSAVYYC & ALGDREGGRALI & FGTG & 15 & 2 \\
\hline \multirow[t]{31}{*}{ TCR beta } & QDSAVYLC & ASSFQTGGAETLY & FGSG & 13 & 6 \\
\hline & NEMAVFLC & ASSSPTGGWNAEQF & FGPG & 14 & 6 \\
\hline & EDSAVYLC & ASSNYAEQF & FGPG & 9 & 6 \\
\hline & DDSATYFC & ASSLGTGDAEQF & FGPG & 12 & 6 \\
\hline & DDSATYFC & ASSLRDNGDTQY & FGPG & 12 & 6 \\
\hline & DDSATYFC & ASSOEAGGVDTQY & FGKG & 13 & 4 \\
\hline & NEMAVFLC & ASSPRTTSGNTLY & FGEG & 13 & 4 \\
\hline & NEMAVFLC & ASSPPTGSPNERLF & FGHG & 14 & 4 \\
\hline & EDRGLYLC & GARDLWGGKNTLY & FGAG & 13 & 4 \\
\hline & DDSATYFC & ASSQEGLDSYEQY & FGPG & 13 & 4 \\
\hline & NEMAVFLC & ASSIEDSGTEVF & FGKG & 12 & 4 \\
\hline & QDSAVYLC & ASSLRGHTEVF & FGKG & 11 & 2 \\
\hline & ODSAVYLC & ASSVRDWGDTQY & FGPG & 12 & 2 \\
\hline & QDSAVYLC & ASSLRNTEVF & FGKG & 10 & 2 \\
\hline & DDSATYFC & ASSQEGWGPYEQY & FGPG & 13 & 2 \\
\hline & DDSATYFC & ASSQGLGNYAEQF & FGPG & 13 & 2 \\
\hline & DDSATYFC & ASSQEGTGGYAEQF & FGPG & 14 & 2 \\
\hline & DDSATYFC & ASSQDGTGGYAEQF & FGPG & 14 & 2 \\
\hline & DDSATYFC & ASSQGIYEQY & FGPG & 10 & 2 \\
\hline & DDSATYFC & ASSPANSDYT & FGSG & 10 & 2 \\
\hline & DDSATYFC & ASSQDGTIODTQY & FGPG & 13 & 2 \\
\hline & DDSATYFC & ASSPDWDTTGQLY & FGEG & 13 & 2 \\
\hline & DDSATYFC & ASSQDRSSSAETLY & FGSG & 14 & 2 \\
\hline & DDSATYFC & ASSQEGTGGKEQY & FGPG & 13 & 2 \\
\hline & NEMAVFLC & ASSSPTGGWNAWQF & FGPG & 14 & 2 \\
\hline & EDSAVYLC & ASSPRGLYAEQF & FGPG & 12 & 2 \\
\hline & EDSAVYLC & ASSRDWGSEQY & FGPG & 11 & 2 \\
\hline & EDSAVYLC & ASSPDWGDEQY & FGPG & 11 & 2 \\
\hline & SQTAVYFC & ASSGRTTANTEVF & FGKG & 13 & 2 \\
\hline & SQGRTLYC & TCSADGSYEQY & FGPG & 11 & 2 \\
\hline & EYSAMYLC & ASSSGGFAETLY & FGSG & 12 & 2 \\
\hline
\end{tabular}


Table 2 TCRa and $\beta$ chain repertoires of a Th2 polarized T cell line (Continued)

\begin{tabular}{lllll}
\hline EYSAMYLC & ASRDWGETLY & FGSG & 10 & 2 \\
SHSGFYLC & AWSLWSGVANERLF & FGHG & 14 & 2 \\
SQTSLYFC & ASSDFSTEVF & FGKG & 10 & 2 \\
\hline
\end{tabular}

The most dominant TCR alpha sequence is shown in bold.

Mean CDR3a length $12.24 \pm 0.20$ (SE) $(n=49)$.

Mean CDR3 $\beta$ length $12.25 \pm 0.20(\mathrm{SE})(\mathrm{n}=51)$.

(Figure 3A). Interestingly, however, while the littermate controls generated a strong IFN $\gamma$ response, this was absent after the initial recall in the TCR $\alpha$ transgenics at Day 28 $(P<0.05)$ (Figure 3B). This suggested that use of this receptor was less effective at maintaining IFN $\gamma$ transcription. When mice were boosted, we observed an IFN $\gamma$ response in littermates but not in TCR $\alpha$ transgenics (Figure 3C).

T cells from the TCR $\alpha$ chain transgenics were harvested at Day 32, cultured with peptide for $48 \mathrm{~h}$ and CDR3 analysis of the $\mathrm{CD}^{+} \mathrm{CD}^{+} 9^{+}(\mathrm{n}=50)$ and $\mathrm{CD} 4{ }^{+} \mathrm{CD}^{-} 9^{-}(\mathrm{n}=48)$ cells was carried out. The lack of an IFN $\gamma$ response in TCR $\alpha$ transgenics after boosting correlated with selection of a single shared V $\beta 2$ partner chain, as demonstrated by TCR sequencing and by spectratyping using $\mathrm{V}$ gene specific primers (Figure 3D, E). All the $\mathrm{CD} 4{ }^{+} \mathrm{CD} 69^{+}$cells expressed the same TCR $\beta$ chain, TRBV2 TRBJ2-5 with an elongated 13-amino acid CDR3 region ASSQAGTGEDTQY. Thus, the defective IFN $\gamma$ recall response was associated with the clonal expansion of a population of cells expressing a single TRBV2 TRBJ2-5 chain with an elongated CDR3.

\section{Cytokine polarization evolves in cultured cell lines in line with favored TCRaß selection}

In order to look in more detail at the relationship between progressive polarization and focusing of the TCR repertoire, we set out to look at polarization and TCR $\beta$ selection during progressive re-stimulation of $\mathrm{T}$ cell lines in vitro. This was done in the absence of exogenous polarizing factors in the medium. This allowed us to further explore the possibility that, with progressive re-stimulation and selection, there may be increasing focus on particular TCR pairs, leading to impaired Th1 responses and gradual promotion of Th2 responses. Primed draining LNC were used to establish $\mathrm{T}$ cell lines in vitro. Elongated CDR3 TCR $\alpha$ chain transgenic lines 20 and 34, short CDR3 TCR $\alpha$ chain transgenic line 30 and transgene negative littermate controls were primed with peptide in CFA and, 10 days later, LNC were harvested and T cell lines established. Line 20 and line 34 TCR $\alpha$ transgenic cells rapidly selected dominant TCR $\beta$ chain expansions (Figure 4A). By the fourth re-stimulation, over half of the TCR $\beta$ repertoires for the TCRV $\alpha$ transgenic lines comprised a single V $\beta$ chain (although differing between the founder lines: VRBV31 TRBJ2-3; CAWSLGGGAETLYF in the case of line 20 and TRBV13-1 TRBJ2-7; CASSDTGGAQSSYEQY in line 34) and by the sixth re-stimulation, the TCRV $\beta$ repertoire was composed almost exclusively of this V $\beta$ chain. These studies, along with the studies shown above in Figure 3, argue that several different TCR $\beta$ chains can pair with the elongated TCR $\alpha$ chain to yield the desired pMHC specificity and that in a given mouse or T cell line, one of several possible sequences may acquire clonal dominance. This selection of TCR $\beta$ chains in the context of pMHC activation was confirmed by spectratyping (Figure 4B). As early as the second re-stimulation, CD4 T cell lines from line 20 TCR $\alpha$ transgenics show constrained spectra, with a significant contraction of the TCRV $\beta$ chain repertoire for several $\mathrm{V} \beta$ gene families while spectra from littermate control $\mathrm{T}$ cell lines show TCRV $\beta$ diversity (Figure 4B).

We then looked at this TCR focusing during evolution of a given $\mathrm{T}$ cell line in relation to skewing of cytokine production. At the same time as making cDNA at each re-stimulation for TCR sequence analysis and spectratyping, cytokine production was analyzed by ELISA and RNA used for real-time analysis of subset-specific transcription factors. With progressive re-stimulations in vitro, the reciprocal nature of Th1 and Th2 polarization in littermate controls and TCR $\alpha$ transgenic lines with the shorter compared to those with elongated CDR3 regions is seen. TCR $\alpha$ transgenics with the elongated CDR3 region (line 20) make little or no IFN $\gamma$, but, after a lag of one restimulation, make large amounts of IL-4, IL-5 and IL-13 (Figure 4C). TCR $\alpha$ transgenic lines with the shorter CDR3 region (line 30) and non-transgenic controls make IFN $\gamma$, but no IL-4, IL-5 and IL-13. In line with this, GATA-3 transcription is progressively up-regulated in TCR $\alpha$ elongated CDR3 transgenic cultures compared with littermate controls (Figure 4D).

There is no bias of the TCRV $\beta$ chain repertoire in naïve TCRV $\alpha$ chain transgenic splenocytes at Day 0 (Additional file 2A), or in a primary response in draining lymph nodes at Day 10 post-immunization as demonstrated by spectratype analysis (Additional file 2B).

\section{Generation of TCRa $\beta$ transgenics}

The likely interpretation of the simultaneous appearance of dominant TCR $\beta$ chain sequences in the TCR $\alpha$ chain transgenic lines, adoption of a spontaneous Th2 phenotype and impaired Th1 program, was thus that features of this preferred TCR $\alpha \beta$ pair were incompatible with effective maintenance of Th1 activation and, therefore, 
Table 3 TCRa and $\beta$ chain repertoires ot a Th17 polarized T cell line

\begin{tabular}{|c|c|c|c|c|c|}
\hline & & CDR3 region & & CDR3 length & $\%$ \\
\hline \multirow[t]{16}{*}{ TCR alpha } & EDSGTYFC & AAANTNTGKLT & FGDG & 11 & 44 \\
\hline & EDSGTYFC & AAEDNNNNAPR & FGAG & 11 & 16 \\
\hline & EDSGTYFC & AAMNYNQGKLI & FGQG & 11 & 6 \\
\hline & EDSGTYFC & AAVDYNQGKLI & FGQG & 11 & 4 \\
\hline & TDSGTYLC & AMDMNNNNAPR & FGAG & 11 & 4 \\
\hline & EDSGTYFC & AAEAPSSGQKLV & FGQG & 12 & 4 \\
\hline & GDSAVYFC & AVSVDNYAQGLT & FGLG & 12 & 4 \\
\hline & EDSGTYFC & AAMNTNTGKLT & FGDG & 11 & 2 \\
\hline & EDSGTYFC & AANNYNQGKLI & FGQG & 11 & 2 \\
\hline & EDSGTYFC & AAEGNSGTYQR & FGTG & 11 & 2 \\
\hline & EDSGTYFC & AAEDSGGNYKPT & FGKG & 12 & 2 \\
\hline & EDSGTYFC & AAYNYAQGLT & FGLG & 10 & 2 \\
\hline & EDSGTYFC & AAEADTNAYKVI & FGKG & 12 & 2 \\
\hline & EDSGTYFC & AAGPHNNNAPR & FGAG & 11 & 2 \\
\hline & TDSGTYLC & AMER6TNTGKIJT & FGDG & 12 & 2 \\
\hline & SDSAVTPC & AARSDTNAYKVI & FGKG & 12 & 2 \\
\hline \multirow[t]{27}{*}{ TCR beta } & EDSAVYLC & ASSSTGGAHYAEQF & FGPG & 14 & 8 \\
\hline & QDSAVYLC & ASSLVGQGDTQY & FGPG & 12 & 6 \\
\hline & DDSATYFC & ASSQDQISQNTLY & FGAG & 13 & 6 \\
\hline & DDSATYFC & ASSQDLGTSNERLF & FGHG & 14 & 6 \\
\hline & SQTSVYFC & ASGDSAGGNSPLY & FAAG & 13 & 4 \\
\hline & SQTSVYFC & ASAWGENTLY & FGAG & 10 & 4 \\
\hline & ODSAVYLC & ASSLDTGYTEVF & FGKG & 12 & 2 \\
\hline & QDSAVYLC & ASSLGQGTEVF & FGKG & 11 & 2 \\
\hline & QDSAVYLC & ASSLAPGQGDERLF & FGHG & 14 & 2 \\
\hline & QDSAVYLC & ASSLDQTNERLF & FGHG & 12 & 2 \\
\hline & ODSAVYLC & ASSLAGANTGQLY & FGEG & 13 & 2 \\
\hline & QDSAYYLC & ASSLDAGQNYAEQF & FGPG & 14 & 2 \\
\hline & QDSAVYLC & ASSPPDTYEQY & FGPG & 11 & 2 \\
\hline & ODSAVYLC & ASSPQGYQDTQY & FGPG & 12 & 2 \\
\hline & ODSAYYLC & ASSLDWGEGNTLGL & FGAG & 14 & 2 \\
\hline & SQTSVYPC & ASGDGTGGRDEOP & FGPG & 13 & 2 \\
\hline & SQTSVYFC & ASG6GTASNERLF & FGHG & 13 & 2 \\
\hline & SOTSVYFC & ASGETANTEV & FGKG & 10 & 2 \\
\hline & SQTSVYPC & ASSDAGTGRDTEVF & FGKG & 14 & 2 \\
\hline & SQTSVYFC & ASSDAAGGFIAEQF & FGPG & 14 & 2 \\
\hline & SQTSVYFC & ASSDAGVTGQLY & FGEG & 12 & 2 \\
\hline & SQTSVYFC & ASSDGQNTLY & FGAG & 10 & 2 \\
\hline & SQTSVYFC & AGSGDWGDEQY & FGPG & 11 & 2 \\
\hline & SQTSVYFC & ASSAGQQDTQY & FGPG & 11 & 2 \\
\hline & SQTSVYFC & ASSDAGTGRDTEVF & FGKG & 14 & 2 \\
\hline & SQTSVYFC & ASSDEGTKPDTEVF & FGKG & 14 & 2 \\
\hline & SQTSVYFC & ASSDDRVNERLF & FGHG & 12 & 2 \\
\hline
\end{tabular}

Table 3 TCRa and $\beta$ chain repertoires ot a Th17 polarized $\mathbf{T}$ cell line (Continued)

\begin{tabular}{lllll} 
SQTSVYFC & ASSPSGTGSYEQY & FGPG & 13 & 2 \\
SQTSVYFC & ASSDDRVNERLF & FGHG & 12 & 2 \\
DDSATYFC & ASSQEGTGGDEQY & FGPG & 13 & 2 \\
DDSATYPC & ASSQEKGQGYAEQF & FGPG & 14 & 2 \\
NQTSVYFC & ASSSPFNSYNSPLY & FAAG & 14 & 2 \\
NQTSVYFC & ASSLRTGGGGTEVF & FGKG & 14 & 2 \\
SHSGFYLC & AWSHNRGNSDYT & FGSG & 12 & 2 \\
EYSAMYLC & ASSGPSTGRDTEVF & FGKG & 14 & 2 \\
EYSAMYLC & ASSRGDWGNEQY & FGPG & 12 & 2 \\
NEMAVFLC & ASSMGTYAEQF & FGPG & 11 & 2 \\
EDSAVYLC & ASSSLGGRNYAEQF & FGPG & 14 & 2 \\
EDSAVYLC & ASSLGLGAETLY & FGSG & 12 & 2 \\
\hline
\end{tabular}

The most dominant TCR alpha sequence is shown in bold. Mean CDR3a length $11.14 \pm 0.06(\mathrm{SE})(n=50)$. Mean CDR3 $\beta$ length $12.70 \pm 0.18$ (SE) $(n=50)$.

favored emergence of a Th2 response. We therefore expressed one of the immunodominant, selected TCR $\beta$ sequences (TRBV31 TRBJ2-3; CAWSLGGGAETLYF) in the pT $\beta$ expression cassette (Figure 2C), generated TCR $\beta$ transgenics, and crossed these to line 20 TCR $\alpha$ transgenics on the same NOD.E background.

\section{TCRa $\beta$ transgene impacts on ex-vivo T cell phenotype}

To assess the functional impact of the TCR $\alpha \beta$ on primary ex-vivo T cell responses to peptide, TCR $\alpha \beta$ transgenics and littermate controls were primed with peptide/CFA, again supplying a maximal Th1-skewing environment. At Day 10, T cell responses were analyzed ex-vivo and T cell lines established. While TCR $\alpha \beta$ transgenics, as would be expected, show enhanced $\mathrm{T}$ cell proliferation responses to peptide, IFNY and IL-17 responses were absent, and they made substantial amounts of IL-9 (Figure 5A). As before, immediately ex-vivo we could detect no IL-4, IL-5 or IL13 (data not shown). The absent production of IFN $\gamma$ and IL-17 and enhanced production of IL-9 observed in the $\mathrm{TCR} \alpha \beta$ transgenic line was seen in the context of priming with the Th1 promoting adjuvant CFA making this result all the more striking. IL-10 production was not significantly different between the groups.

The phenotype of the TCR $\alpha \beta$ transgenic lines was further confirmed by real time PCR for IFN $\gamma$, GATA-3 and ROR $\gamma$ t. The TCR $\alpha \beta$ transgenic lines expressed high levels of GATA-3 ( $P<0.004$; unpaired t-test) and low levels of IFN $\gamma$ and RORyt relative to the littermate controls in keeping with a Th2 phenotype (Figure $5 \mathrm{~B}$ ). Furthermore, GATA-3 expression increased with successive re-stimulations, while RORyt expression decreased in keeping with the reduction in IL-17 production (Figure 5C). The level of T-bet transcription, however, showed no obvious 
pattern through re-stimulations of the TCR transgenic or WT lines (Additional file 3). This is in line with an increasingly complex model for T-bet in the Th1 program: in several models, Th2 polarization occurs in the face of T-bet transcription [31,32].

Because our investigations had used CFA priming, it was important to gauge the effect of immunizing TCR $\alpha \beta$ double transgenic, TCR $\alpha$ chain single transgenic and littermate control transgenics with peptide in IFA lacking Th1-skewing killed mycobacteria (with the caveat that this is a less effective way of priming $\mathrm{T}$ cell responses). At Day 10 , LNC were harvested and ${ }^{3} \mathrm{H}$-thymidine incorporation and cytokine production determined ex-vivo. The results are in line with the larger pMHC-specific $\mathrm{T}$ cell response in the TCR $\alpha \beta$ transgenics, but confirm the Th2 bias: TCR $\alpha \beta$ transgenic cells respond strongly to peptide making IL-4, IL-5, IL-9, IL-10 and IL-13, but no IFNy or IL-17 (Figure 5D). TCR $\alpha$ chain transgenics, and littermate controls made IL-5 and small amounts of IL-10 only (Figure 5D). This is in keeping with the TCR $\alpha \beta$ receptor supporting a Th2 phenotype.

\section{Addressing alternative hypotheses for cytokine-skewing in the TCR transgenics}

The TCR $\alpha \beta$ transgenic lines make more IL-2 than littermate controls, indicating $\mathrm{T}$ cell survival potential (Figure 5A). The high IL-2 response in the TCR $\alpha \beta$ transgenic line, taken together with the high IL-9 and IL-10 response, implies that there is no global failure of $\mathrm{T}$ cell activation/survival per se, but merely a cytokinedeviated response. This appears to argue against a possible alternate hypothesis, that increased precursor number may have caused greater competition for IFN $\gamma$ signals and decreased $\mathrm{T}$ cell fitness and/or memory [33-35]. To further address this issue, we immunized TCR $\alpha \beta$ transgenics and littermate controls on Day 0 and Day 28 with PLP 56 to 70 in CFA and IFA, respectively, and looked at markers of cell activation and cell survival by real-time PCR and fluorescence activated cell sorter (FACS). Real-time PCR analysis of B-cell lymphoma-extra large $(B c l x l)$ expression gave no indication of an enhanced propensity to apoptosis (Additional file 4A). Anti-apoptotic proteins, such as Bclxl, are involved in protecting mitochondrial integrity, for example, in the context of limiting growth factors [36]. Bclxl is induced on T cell activation and enhanced by costimulation of CD28 [37], and it is generally considered that over-expression of B-cell lymphoma 2 (Bcl-2) or Bclxl in $\mathrm{T}$ cells prevents death by neglect $[33,38,39]$. Furthermore, data from Gett and colleagues indicate that induction of Bclxl on sustained activation depends on stimulation strength and is associated with resistance to apoptosis, Bclxl increase being greatest in T cells that had received prolonged stimulation. If TCR transgenic cells were incapable of fully functional stimulation and destined for some form of sub-optimal stimulation or death by neglect, one would predict diminished activation of Bclxl in the transgenic response. In fact, we found no difference in $B c l x l$ expression. Taken together with the other evidence shown here, including the strong IL-2 response on activation, we interpret the findings to mean that there is no deficit in activation of the response through the transgenic receptor, but rather, deviation of the transcriptional response to an altered cytokine profile. Furthermore, phenotypic analysis of the primed lymphoid populations at Day 28 showed no difference in activation/fitness as indicated by staining for CD127 (Additional file 4B). It has been shown by Whitmire and colleagues in a transgenic lymphochoriomeningitis virus (LCMV) response cell transfer model that only when the number of transferred $\mathrm{T}$ cell precursors was low did they generate fully functional memory cells that were CD127/IL-7R (high), with full capacity to produce cytokine and proliferate. Testing therefore whether it was possible that an excess of responder cells here correlated with a response phenotype that was in some way impaired, we analyzed $\mathrm{T}$ cell expression of CD127, and found that transgenic cells had enhanced, not reduced expression. Taken together with the other evidence presented here, this makes it unlikely that this was a model of sub-optimal activation. Furthermore, expression of CD62L was similar in the transgenic and littermate responder populations (Additional file $4 \mathrm{C}$ ). Thus, the indication from IL-2 release, as well as apoptosis and activation markers is that the phenotype observed here constitutes an actively skewed functional preference, rather than a failure to trigger properly by the transgenic receptors.

It was hypothetically possible that injection of cognate peptide into a single chain $\mathrm{TCR} \alpha$ and $\mathrm{TCR} \alpha \beta$ transgenic mice had triggered a cytokine storm due to the large number of responding $T$ cells, and this had in turn caused thymic apoptosis leading randomly to a skewed cytokine outcome in surviving cells. To address this we conducted additional studies. 'Cytokine storm' is a term derived from the systemic response in toxic or septic shock [40]. Here, an acute, excessive spike of systemic pro-inflammatory cytokines leads to downstream events, often including large-scale lymphocyte apoptosis. In our studies the positive control stimulus of SEB led to the predicted spike in systemic proinflammatory cytokines, such as IFN $\gamma$ and TNF $\alpha$ at $2 \mathrm{~h}$, but no systemic change in cytokines was detected after injection of peptide/CFA (Additional file 5A, B). It was nevertheless possible that even in the absence of a systemic response there may have been some acute, storm-driven change in thymic populations accounting in a non-specific way for cytokine skewing. While SEB had a dramatic effect on overall thymocyte numbers and $\mathrm{CD} 4 / \mathrm{CD} 8$ ratio in littermate control as well as 


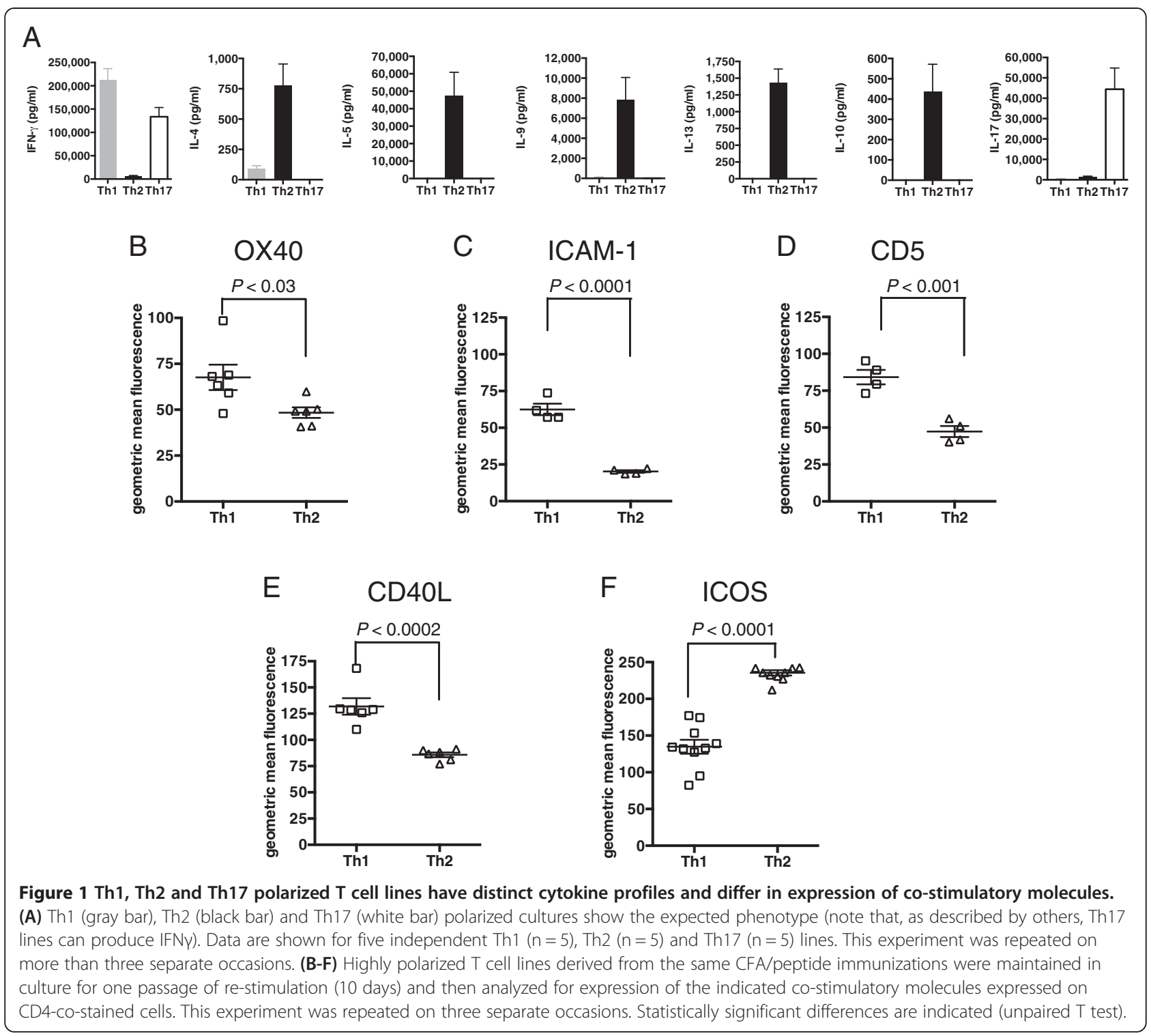

TCR $\alpha$ and TCR $\alpha \beta$ transgenics, no such effect was seen with cognate peptide (Additional file 5B). None of the peptide-primed non-transgenic controls showed preferred TCR $\beta$ chains in sorted CD4 SP cells from thymocytes (Additional file $5 \mathrm{C}$ ). However, in one out of four of the mice analyzed, TCR $\beta$ chains in sorted CD4 SP cells from thymocytes in peptide-primed TCR $\alpha$ transgenics show preferential selection of a preferred TCR heterodimer, $44 \%$ of TCRs using a common TCR $\beta$ chain (Additional file 5D). On the basis of these experiments, the Occam's razor hypothesis, that TCR $\alpha$ chains of differing structures and avidities can influence cytokine program, appears more likely than cytokine preference emerging as a stochastic event in the aftermath of a cytokine storm.
T cell lines with TCRa $\beta$ receptor have low binding avidity

We previously predicted from molecular modeling studies that the elongated CDR3 region of the TCR $\alpha$ chain, when paired with a preferred TCR $\beta$ chain, might result in a lower avidity interaction between the TCR and its pMHC ligand $[20,22]$. We therefore started by reappraising functional avidity in a peptide titration of Th1, Th2 and Th17 polarized, non-transgenic $\mathrm{T}$ cell lines cultured for eight days in polarizing medium and looking at IFN $\gamma$, IL-4 and IL-17 ELISPOTs, respectively. In these shortterm lines, to achieve a response of $100 \mathrm{SFC} / 10^{6}$ cells requires about 3 times the peptide concentration in the Th1 lines compared to Th17, and about 250 times the peptide concentration in the Th2 lines compared to Th17 (Figure 6A). 
A

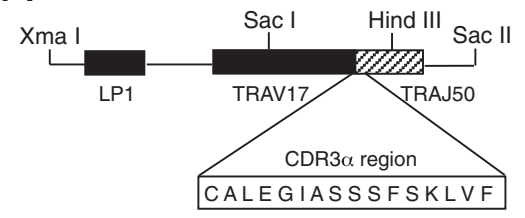

C

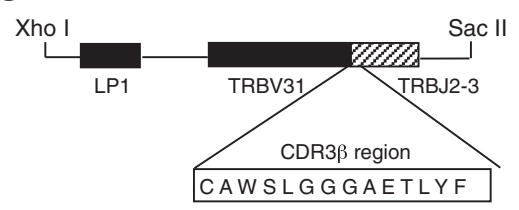

$\mathrm{B}$

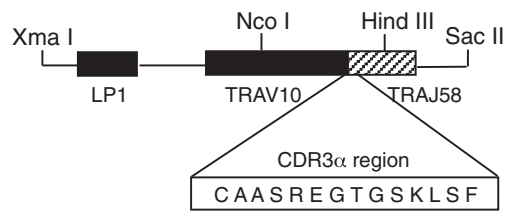

Figure 2 Schematic diagram illustrating construction of the Th2 derived TCRa chain transgene with an elongated CDR3 region, Th1 TCRa chain transgene with a short CDR3 region, and Th2 TCR $\boldsymbol{\beta}$ chain transgene. (A) The Th2-derived TCRa chain transgene with an elongated CDR3 region, (B) Th1 TCRa chain transgene with a short CDR3 region, and (C) Th2 TCR $\beta$ chain transgene showing the recombined $V$ and $J$ gene segments and the amino acid sequence of the CDR3 regions. Intronic sequences flank the $3^{\prime}$ and $5^{\prime}$ ends of the coding regions and also separate the leader sequence (LP1) from the main coding region of the $V$ gene. Transgenes were cloned into TCR a or $\beta$ chain expression vectors that contain TCRa or $\beta$ constant regions and endogenous promoter elements, using Xma I/Sac II sites for the TCRa and Xho I/Sac II sites for the TCR $\beta$ transgene.

We next looked at tetramer binding characteristics of Th1, Th2 and Th17 polarized, non-transgenic T cell lines cultured for eight days in polarizing medium and prepared from the same initial pool of primed LNC, using $\mathrm{H} 2-\mathrm{A}^{\mathrm{g} 7}$ tetramers loaded with either PLP56 to 70 or an irrelevant $\mathrm{H} 2-\mathrm{A}^{\mathrm{g} 7}$-binding peptide (CLIP103 to 117, PVSKMRMATPLLMQA). At all concentrations of tetramer tested, a significantly greater proportion of Th1 and Th17 polarized cells bound tetramer compared to Th2 cells despite equivalent levels of cell surface CD3 (Figure 6B, C). Similarly, in a peptide titration to examine the functional avidity of short-term T cell lines from TCR $\alpha \beta$ transgenics relative to littermates, an equivalent number of IL-4 spotforming cells in the TCR $\alpha \beta$ transgenics require approximately 50 times the peptide concentration required for the IFN $\gamma$ response in littermates (Figure 6D). We then compared tetramer binding characteristics of $\mathrm{T}$ cell lines derived from the Th2-type TCR $\alpha \beta$ transgenic cells, TCR $\alpha$ chain transgenics with an elongated CDR3 and Th1-type cells from non-transgenic littermate controls. As tetramer concentration increased, a higher frequency of Th1 cells from the control littermate bound tetramer. However, no tetramer binding was detectable for the TCR $\alpha \beta$ transgenic cells, indicating that the avidity of the interaction with the TCR $\alpha \beta$ cells was too low for detection (Figure 6E). The TCR $\alpha$ chain transgenics with an elongated CDR3 had an intermediate binding avidity. We demonstrated a functional interaction between the tetramer and TCR $\alpha \beta$ transgenic $\mathrm{T}$ cells by measuring cytokine production from transgenic cells cultured in the presence of plate-bound tetramer. In keeping with the Th2 phenotype, IL-4, IL-5, IL-9 and IL-13 but not IFN $\gamma$ were detected (Figure 6F).

The Th17 polarized T cell lines produced less IL-17 with each successive re-stimulation such that by the fourth re- stimulation cytokine production was more in keeping with that of a Th1 cell line (Figure 7A, B). We hypothesized that this shift in cytokine production would be accompanied by a reduction in tetramer binding avidity and longer TCRV $\alpha C D R 3$ length as $\mathrm{T}$ cells with a IFN $\gamma$ producing phenotype clonally expand. In keeping with this, we observed a reduction in tetramer binding avidity between the first and fourth re-stimulations of polarized Th17 lines such that at the fourth re-stimulation, tetramer binding curves for Th1 and Th17 lines overlapped (Figure 7C, D). TCR repertoire analysis at the first and fourth restimulations confirmed that the change in cytokine production and tetramer binding avidity occurred alongside an increase in average TCRV $\alpha C D R 3$ length (Figure 7E). The mean TCRV $\alpha C D R 3$ lengths for the first and fourth re-stimulations are $10.95+0.22(\mathrm{SE})(\mathrm{n}=37)$ and $11.39+$ 0.21 (SE) $(\mathrm{n}=51)$, respectively, $(P=0.038)$. The difference in mean CDR3 $\alpha$ length between the first and fourth restimulation shows progression to a TCR repertoire with longer CDR3 $\alpha$ regions as cells lose their IL-17 producing phenotype and become more Th1-like in their tetramer binding characteristics and cytokine production.

In light of previous observations in TCR transgenics, notably the early studies by Hosken and colleagues [41] using the DO11.10 TCR transgenic line, it might be predicted that the Th2 TCR transgenic-skewed polarization may be overcome by altering peptide dose. Certainly, among the many factors that can skew cytokine bias would be peptide dose itself. In the DO11.10 TCR transgenic studies, it was shown that under otherwise equivalent in vitro primary culture of naïve cells, mid-range peptide doses favored the generation of moderate IFN $\gamma$ responses, while either higher or lower doses favored a switch to development of more Th2-like responses, giving 


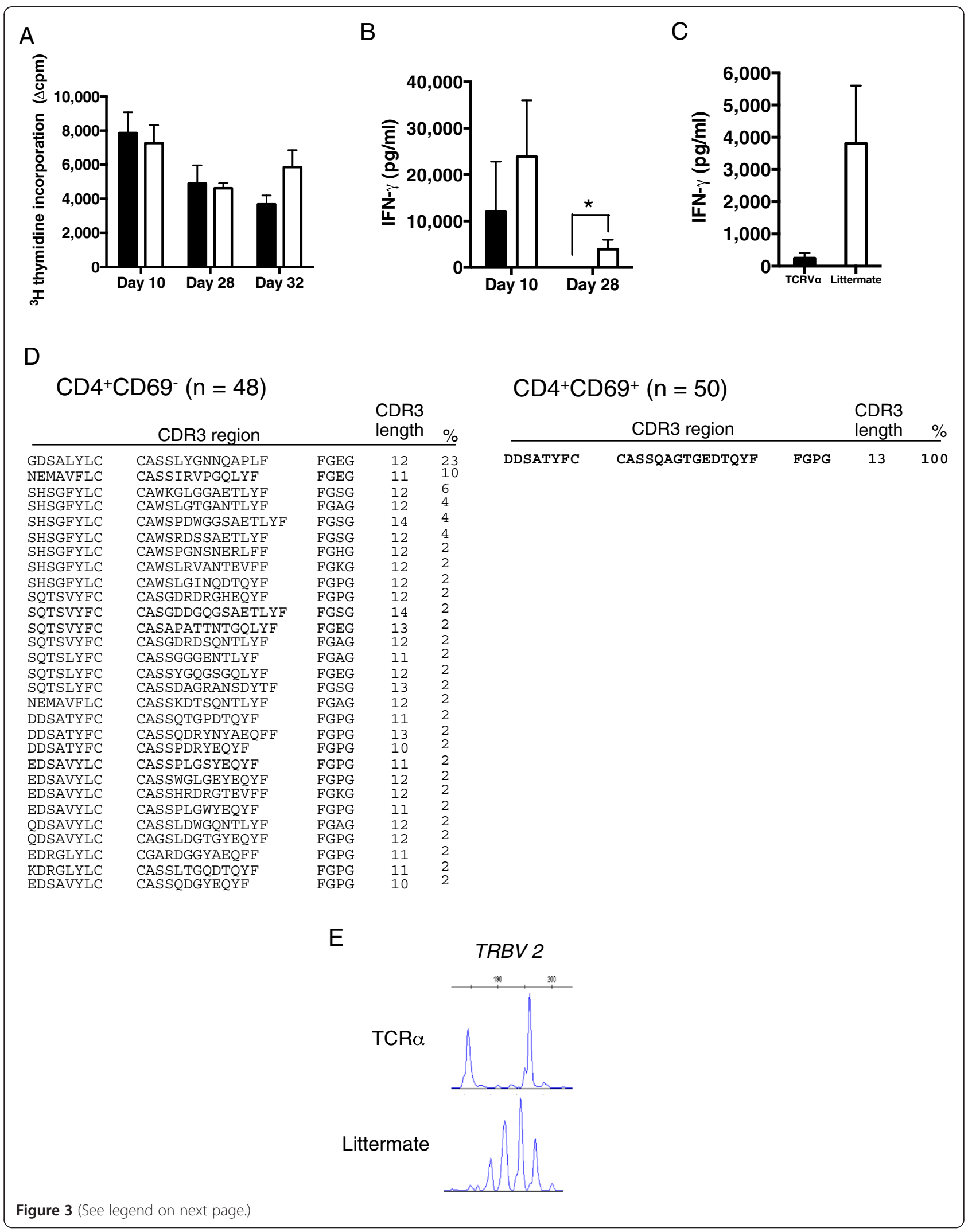


(See figure on previous page.)

Figure 3 The ex-vivo response of TCRa transgenic T cells show impaired IFN $\gamma$ response and selection of a preferred TCR $\beta$ partner chain. (A) TCRa chain transgenic and littermate controls were immunized with PLP 56 to 70/CFA on Day 0 and PLP 56 to 70/IFA on Day 28. T cell proliferation is similar in the two groups. Data shown are mean values \pm SE (TCRa transgenic (black bars), $n=4$ mice at Day 10,6 at Day 28 and 7 at Day 32; littermate controls (white bars), $n=8$ mice at Day 10, 8 at Day 28 and 9 at Day 32). The data are representative of three independently performed experiments. (B) Immediately ex-vivo at Day 10, both groups make similar amounts of IFNy, but at Day 28 no IFNy response is seen in the TCRa transgenics (* $P<0.05$; Mann-Whitney $U$ test) or subsequently after re-challenge at Day 32, (C) TCRa transgenics show an impaired IFNy response compared to controls. (D) T cells from the TCRa chain transgenics were harvested at Day 32, cultured with peptide for $48 \mathrm{~h}$ and TCR 3 chain CDR3 analysis of $\mathrm{CD}^{+} \mathrm{CD}^{+} 9^{+}$( $\mathrm{n}=50$ sequenced receptors from cDNA of bulk, sorted T cell lines) and $\mathrm{CD} 4^{+} \mathrm{CD} 69^{-}(\mathrm{n}=48$ sequenced receptors from cDNA of bulk, sorted T cell lines) cells carried out. The TCRa chain transgenic impaired IFNy phenotype correlates with clonal expansion of a dominant TCRB chain (TRBV2, TRBJ2-5 CDR3 CASSQAGTGEDTQYF). (E) Spectratyping analysis of CD4 ${ }^{+}$CD69 ${ }^{+}$TCRa chain transgenic and littermate control cells was carried out using $\vee$ gene specific primers.

the IFNY response curve the form of a bell-shaped curve [41]. We, therefore, performed a set of experiments in our system to examine the behavior of the Th2-derived transgenic TCR across a checker-board of low to high peptide priming dose and a low to high in vitro re-stimulation dose. Our previous experiments had typically utilized a priming and re-stimulation dose of $25 \mu \mathrm{g} / \mathrm{ml}$, corresponding to $13 \mu \mathrm{M}$ towards the upper-end of the concentration range that had been tested by Hosken and colleagues using naïve $\mathrm{T}$ cells in vitro. We initially primed Th2 TCR $\alpha \beta$ transgenic mice with peptide at 5, 25 or $125 \mu$ g (Figure 8). Popliteal LNC were then challenged in vitro with a titrated dose of peptide from 0.1 to $100 \mu \mathrm{g} / \mathrm{ml}$. As we had seen before, peptide priming with $25 \mu \mathrm{g} / \mathrm{ml}$ did not trigger an $e x-$ vivo IFN $\gamma$ response, though IFNY could be elicited at either a higher or lower dose of peptide priming, 5 or $125 \mu \mathrm{g} / \mathrm{ml}$. Thus, these findings are reminiscent of the studies by Hosken and colleagues, except that the mid-range peak of IFN $\gamma$ production that had been seen by them for the DO11.10 TCR is here exchanged, using a Th2 TCR, for a low/high range peak of IFN $\gamma$ production. Our curve is the reciprocal of the DO11.10 finding. Furthermore, the midrange dose of priming with $25 \mu \mathrm{g} / \mathrm{ml}$ peptide was associated with increased transcription of both GATA-3 and RORYT. Thus, while there is a constraint on IFNy activation, this is peptide dose dependent and can be overridden by either high or low dose peptide priming.

We then used this checker-board titration to analyze cytokine secretion in $\mathrm{T}$ cell lines from peptide primed Th2 TCR $\alpha \beta$ transgenic mice, assaying their profile after the third re-stimulation in vitro. The findings are summarized in Figure 9. IL-4 responses are depicted in blue, IL-13 in green and IFN $\gamma$ in red. The key arbiter of cytokine profile in vitro appeared to be the dose of peptide used for in vitro re-stimulation of the lines. That is, whether initial priming was with 25 or $125 \mu \mathrm{g}$, the $\mathrm{T}$ cells lines produced relatively large amounts of IL-4 and IL-13 but little or no IFN $\gamma$ when re-stimulated with peptide in the range 0.1 to $10 \mu \mathrm{g} / \mathrm{ml}$. However, irrespective of the initial priming dose, the T cell lines showed an IFNY response when re-stimulated in vitro with $100 \mu \mathrm{g} / \mathrm{ml}$ peptide.
Figure 10 is a schematic summarizing the flow of experiments designed here to test the hypothesis that elongated TCR alpha chain complementarity-determining region 3 favors a Th2-skewed CD4 phenotype.

\section{Discussion}

There has been considerable effort devoted to elucidating the structural biology of the TCR complex, with 10s of structures solved, yet clear models for the way in which the ligand/receptor interaction between pMHC and TCR may give rise to the very diverse array of T cell effector programs have been elusive [42,43].

Most TCR transgenic lines are generated without regard for specific features of the cytokine profile of the parental cell from which they were derived. Experiments in some autoimmune models bear on this insofar as there are examples in which $\mathrm{T}$ cell clones were implicated in an autoimmune effector mechanism and the TCR transgenics derived from them can mediate a spontaneous disease phenotype dependent on preferential use of a similar cytokine profile [44]. Candon and colleagues generated transgenics for the TCR of a selfreactive Th2 clone, showing that a proportion of the mice spontaneously developed autoimmune gastritis characterized by eosinophilic infiltration of the gastric mucosa and Th2 differentiation of transgenic T cells in the gastric lymph node [45]. Appropriate Th polarization is most readily attributed to $\mathrm{T}$ cells engaging $\mathrm{pMHC}$ in the context of an antigen presenting cell (APC) that has been activated by innate signals to provide a particular, polarizing environment [46]. Could another aspect of the polarization reside in the TCR sequence itself? This would have evolutionary value as a contributory mechanism in polarization since, without it, the appropriateness, or otherwise, of the effector response could be at the mercy of influence by any other concurrent processes and/or infections. It is self-evident that there may be TCR structures that are 'vanilla' in nature and capable of being diverted readily to either a Th1 or Th2 program; DO11.10 is the prototypic example [21]. Knowing that TCRs of CD4 cells have been reported across a moderately broad range of affinities and also that affinity/ 


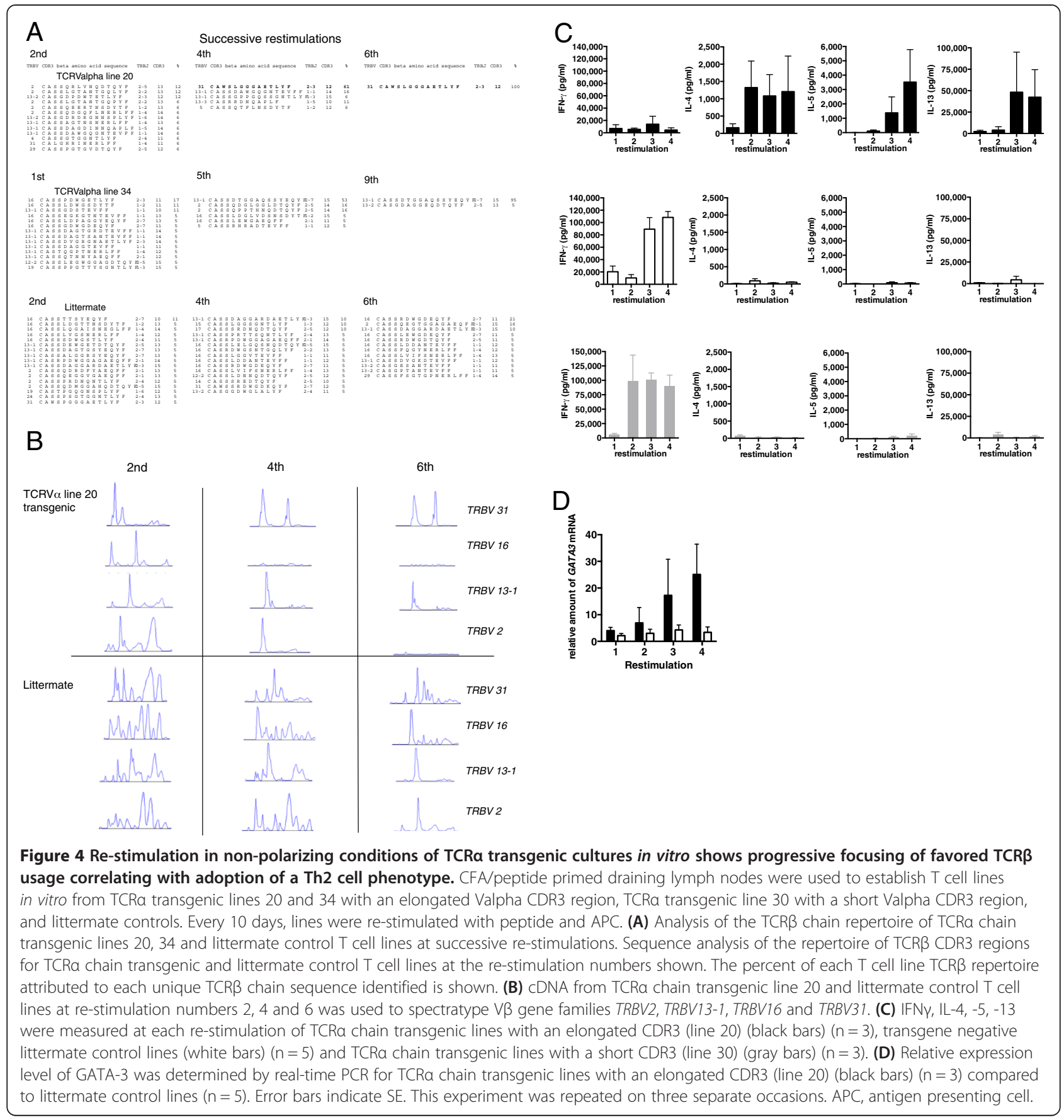

avidity are key determinants of cytokine polarization, it may be predicted that TCRs of different structures would, all else being equal, show inherent bias to different effector profiles. The principle that TCR sequence correlates with function is accepted in the special case of the Treg versus Teff TCR repertoires [47], although even in this setting, phenotypic differences have proved difficult to define [48].

We show, using new TCR transgenic models, that an elongated TCR $\alpha$ derived from a strongly Th2-skewed $\mathrm{T}$ cell line retains imprinting of that effector program to the extent that, even in the face of an overwhelming Th1polarizing environment, such as immunization in CFA containing $M$. tuberculosis, $\mathrm{T}$ cells can proliferate while lacking IFN $\gamma$ responsiveness. While the polarization is mediated through the selection of appropriate CDR3 $\alpha$ regions and the constraints on TCR $\beta$ selection are less apparent, the full Th2 program is clearly dependent on selecting the correct TCR $\alpha \beta$ pair.

A starting point for the studies here was to reappraise more broadly our earlier observations about preferential 

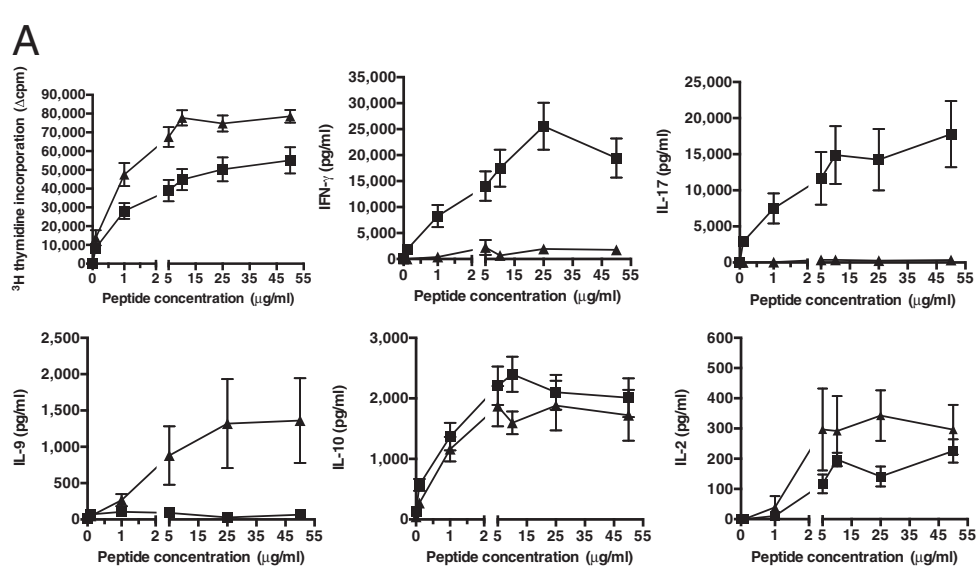

B
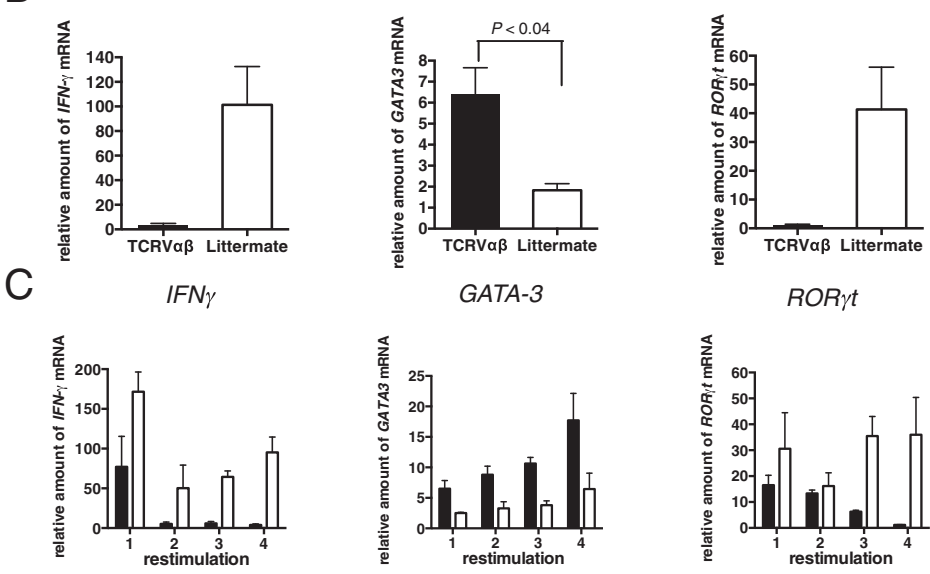

GATA-3
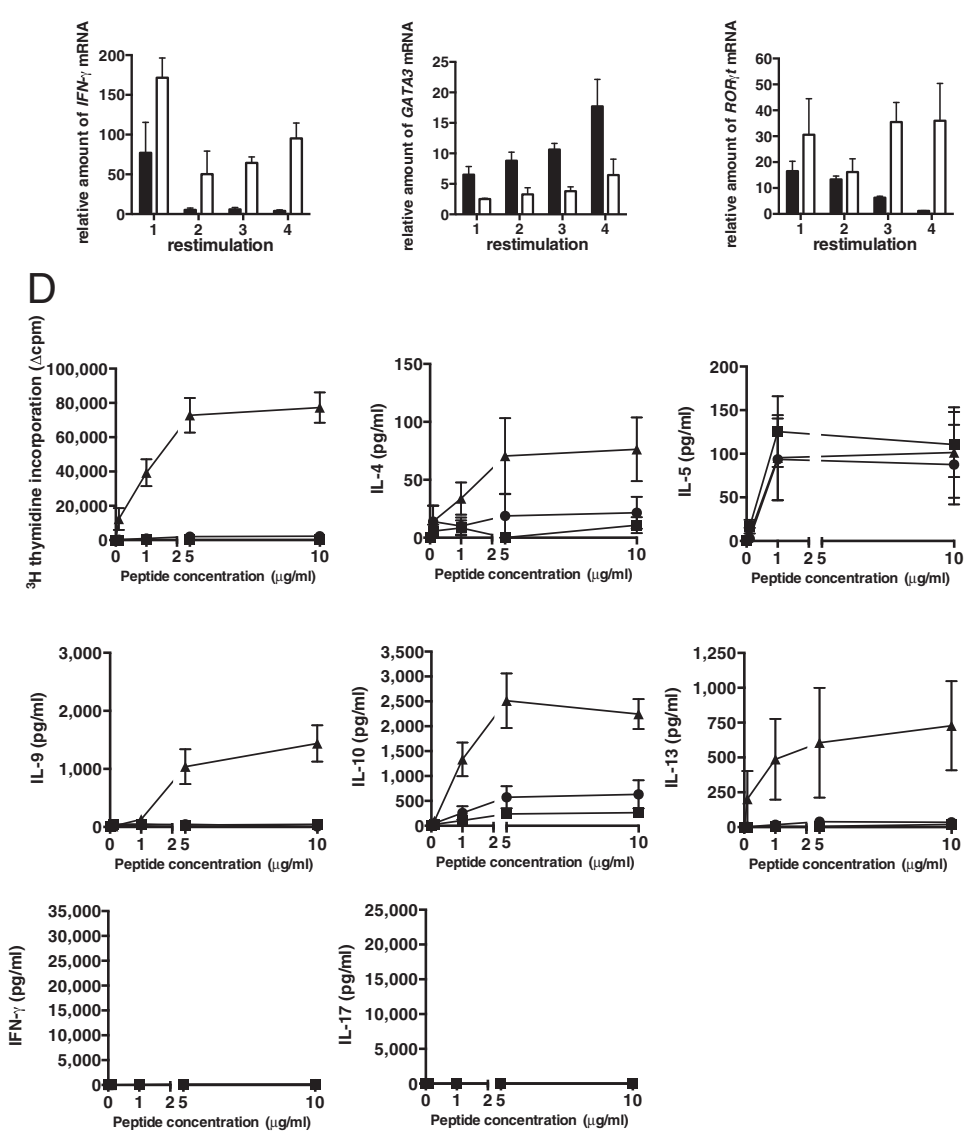

Figure 5 (See legend on next page.) 
(See figure on previous page.)

Figure 5 TCRVa $\beta$ transgene pair impacts on cytokine production and transcriptional profile. (A) TCRaß transgenics or littermate controls were primed with peptide in CFA and DLN cells harvested at Day 10. ${ }^{3} \mathrm{H}$-thymidine incorporation and cytokine production was determined from TCRaß transgenics (filled triangles; $n=6$ ) and controls (filled squares; $n=10$ ). Error bars indicate $\pm S E$. This is representative of three separate experiments. (B) TCRaß transgenic cell lines (black bars) $(n=3)$ and littermate control lines (white bars) $(n=5)$ were established from primed DLN cells from mice primed 10 days earlier with PLP56 to 70/CFA and re-stimulated every 10 days through to four cycles in the absence of any exogenous polarization. (C) At each re-stimulation the relative expression of IFNY, GATA-3 and RORYT was determined. Error bars indicate SE. (D) TCRa $\beta$ (filled triangles; $\mathrm{n}=10$ ), TCRa chain transgenics (filled circles; $n=12$ ), and littermate controls (filled squares; $n=27$ ) were primed with peptide/IFA and at Day 10 , DLN cells were harvested and ${ }^{3} \mathrm{H}$-thymidine incorporation and cytokine production analyzed. These data are representative of three independently performed experiments. CFA, Complete Freund's adjuvant; DLN, draining lymph nodes.

selection of the TCR repertoire. This can be thought of as 'avidity-associated functional maturation' of the response; while it has long been known from many pMHC examples that the TCR repertoire can focus in on sometimes highly dominant receptor usage, we add the observation that this choice is highly influenced by factors driving Th1/Th2 polarization. A key observation, reiterated in the current study, had been that Th2 polarization is associated with CDR3 $\alpha$ chains with somewhat elongated loops. In the present study, we have extended this analysis to investigation of Th17-polarized cultures. Once again, TCR $\beta$ chains remained relatively heterogeneous while TCR $\alpha$ sequences rapidly attain focused, preferential usage; although selected out of the same starting pool, the Th17 receptor usage is dissimilar to either Th1 or Th2 lines. Like Th1 lines, TCR $\alpha$ chains are invariably of the Th1-like, short, CDR3 $\alpha$ type. We found no examples of elongated CDR3 $\alpha$ chains in Th17 cells. This may be taken to mean that, like Th1 cells, Th17 activation is dependent on 'high-end' affinity activation and depends on activation that is incompatible with low affinity TCR activation. This is in line with the relatively easy plasticity from Th17 to Th1 lineages, although it is also known that there are differences between activation signals for Th1 and Th17 activation, such as dependence on PKCO [49]. On the other hand, we found little similarity between the actual CDR3 $\alpha$ sequences selected in Th17 and Th1 cultures. To our knowledge this study constitutes the first report of preferential TCR usage associated with the Th17 phenotype with the associated implications for differential avidity of Th17 cells. Th17 cells are predicted to be at the upper end of the avidity spectrum, with associated implications for differential signaling and synapse formation.

A number of studies have sought to relate changes in the TCR repertoire to the development of the T cell response, although not in the specific context of cytokine programs. Studies of CD8 responses have variously shown either a stochastic relationship between the initial response and the expanded repertoire, or substantial focusing with preferential selection of particular clonotypes, sometimes associated with enhanced avidity [50]. Those examples of CD4 repertoire selection that have been investigated in detail have also tended to focus on the progressive loss of low-affinity clones to achieve the 'best fit' $[51,52]$. What is unclear is how this model could be reconciled with a continuing requirement for differential avidities associated with alternate cytokine programs. Certainly, cells within a Th2 memory population can make IFN $\gamma$ if reactivated in the context of innate Th1 signals [53]. That is, it might not be possible to maintain an overall dominance of Th2 clones in the face of a TCR repertoire progressively shifting to higher avidity. For example, in Th1/Th17 dependent experimental autoimmune encephalomyelitis (EAE) TCR transgenic models, strength of pMHC-TCR interaction is correlated with more aggressive, spontaneous disease [54]. Conversely, decreased CD4 expression by polarized Th2 cells has been shown to contribute to reduced TCR-induced phosphorylation and $\mathrm{Ca} 2+$ signaling [55].

Profiling of co-stimulatory molecules on Th1 and Th2 lines showed differences compatible with the notion of enhanced avidity promoting Th1 differentiation. Upregulation of CD40L expression in Th1 cells is a previously well-documented example of this phenomenon, confirmed here [14]. Up-regulation of ICOS was a strong marker of Th2 differentiation, while CD5 up-regulation was a strong marker of Th1 differentiation. In line with the notion of CD5 up-regulation as a marker of enhanced avidity in Th1 cells, CD5 expression in thymocyte selection is correlated with avidity/signal intensity of the positively selecting TCR-pMHC interaction [56].

For differential engagement between pMHC on the APC and the TCR to lead to these very divergent transcription programs, there must be substantive differences in signaling, from initial formation of the immune synapse. A number of studies have previously considered differences in immune synapse formation and TCR signaling between Th1 and Th2 cells: most of these are compatible with the notion that the synapse leading to Th2 differentiation comprises a less tightly focused, lower avidity complex. Th2, but not Th1 cells, fail to cluster TCR at the cellcell interface due to increased expression of cytotoxic T-lymphocyte antigen 4 (CTLA-4) [57]. In line with this, co-clustering of TCR with CD4 in lipid rafts is more 


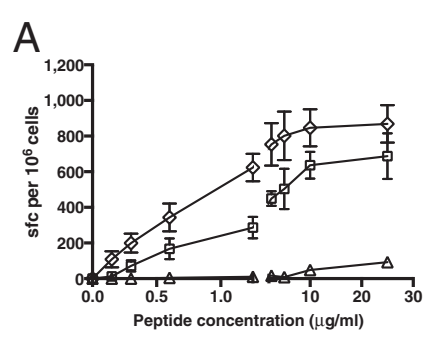

$\mathrm{B}$

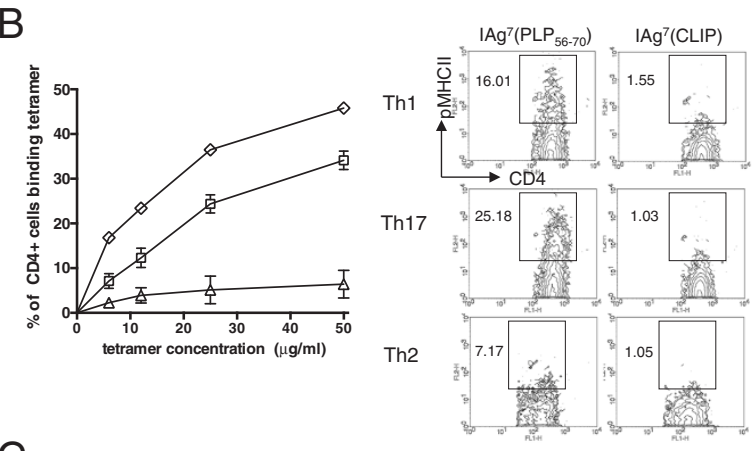

\section{C}

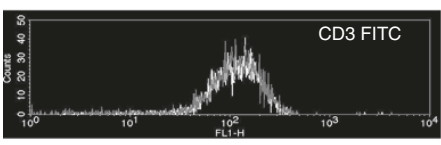

D

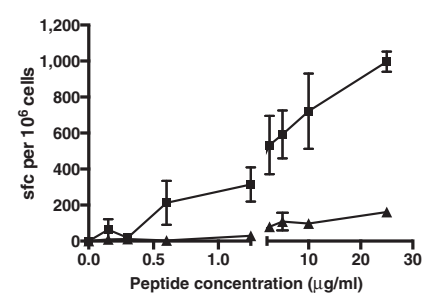

$E$
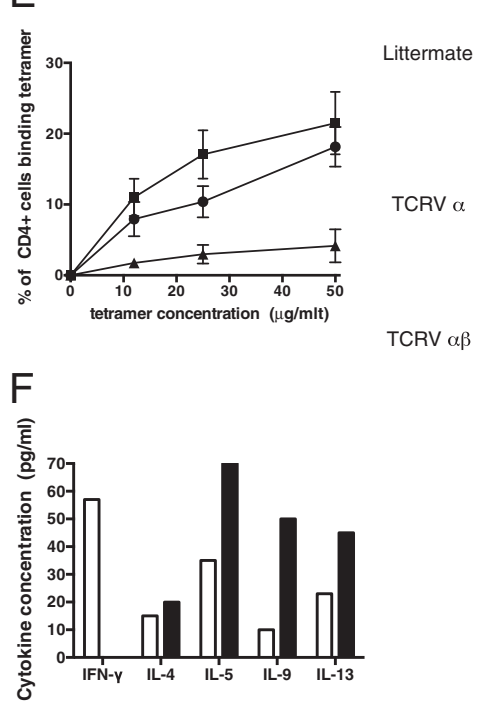

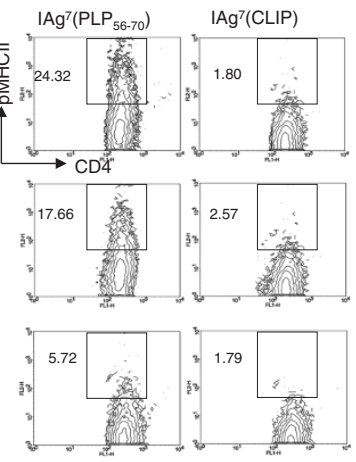

Figure 6 (See legend on next page.) 
(See figure on previous page.)

Figure 6 Th2 derived TCRa $\beta$ has low avidity. (A) ELISPOT assays for Th1 (open squares; $n=4$ ), Th2 (open triangles; $n=3$ ) and Th17 (open diamonds; $n=6$ ) polarized, non-transgenic cell lines cultured for eight days detect IFNy, IL-4 and IL-17 producing cells, respectively, in response to increasing concentration of PLP 56-70 peptide. (B) Th1 (open squares; $n=6$ ), Th2 (open triangles; $n=6$ ) or Th17 (open diamonds; $n=2$ ) polarized, non-transgenic cell lines incubated with $\mathrm{H2}-\mathrm{A}^{9^{7}} / \mathrm{PLP} 56-70$ or control (H2-A $\mathrm{A}^{7} / \mathrm{CLIP}$ 103-117) tetramers on Day 8 after primed draining lymph nodes (DLN) were incubated with peptide. Percentages shown are the difference between staining with $\mathrm{H2}-\mathrm{A}^{97} / \mathrm{PLP} 56-70$ and control (H2-A $\left.\mathrm{A}^{97} / \mathrm{CLIP} 103-117\right)$ tetramers. Data are representative of three separate experiments. (C) Th1 and Th2 polarized cell lines (A, B) have similar levels of CD3 expression. (D) ELISPOT assays for unpolarized, Th2 cytokine producing TCRaß lines (filled triangles; $n=3$ ) and IFNy producing littermate control lines (filled squares; $n=5$ ) cultured in the absence of polarizing cytokines through two successive 10-day cycles of re-stimulation with peptide, detect IL-4 and IFN- $\gamma$ producing cells, respectively, in response to increasing concentration of PLP 56-70 peptide. (E) Unpolarized Th2 cytokine producing TCRaß lines (filled triangles; $n=6$ ), TCRa lines (filled circles; $n=6$ ) and IFNy producing littermate control lines (filled

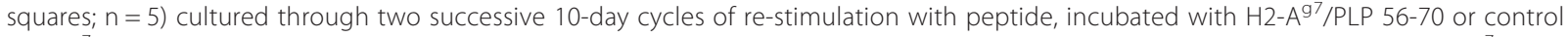
( $\mathrm{H} 2-\mathrm{A}^{97} / \mathrm{CLIP}$ 103-117) tetramers at the concentrations shown. Percentages shown are the difference between staining with $\mathrm{H2} 2-\mathrm{A}^{97} / \mathrm{PLP}$ 56-70 and control (H2-A $\mathrm{A}^{\mathrm{9}} / \mathrm{CLIP}$ 103-117) tetramers. (F) Functional binding of tetramers determined by cytokine production from unpolarized TCRaß lines and littermate controls following incubation with plate bound H2-A ${ }^{97} / P L P$ 56-70 tetramer. Cytokine concentration shown is a total minus background cytokine production for cells incubated with phosphate-buffered saline (PBS) only. The TCRaß transgenic line (black bars) does not make IFNy while the littermate control line (white bars) does. An IFNy absent cytokine profile is elicited from the TCRa $\beta$ transgenic line.

common in Th1 cells [58]. Th2 immune synapses are morphologically distinct, characterized by the failure to exclude CD45 and ICAM-1 from the central zone [59]. These changes are presumed to contribute to diminished strength of signaling. Furthermore, a number of studies have considered mechanisms by which these differences might in turn lead to qualitative signaling differences and alternate transcriptional choices. Strength of signaling has been shown to affect the balance of NFATp and NFATc binding activity, thus directly regulating IL-4 transcription [60]. We predict from our TCR analysis of Th1, Th2 and Th17 lines that Th17 synapse formation and signaling would be distinct from the low avidity interactions characterizing Th2 activation and more reminiscent of Th1 activation.

Jameson and Masopust [61] have summarized a number of studies on the cost to the quality of memory of too much stimulation with the term, 'everything in moderation: better memory by avoiding over-exertion.' Is it possible that our Th2 TCR $\alpha \beta$ transgenic model in some way elicits a response that is sub-optimal through excessive or inappropriate stimulation? While our observations here have focused largely on cytokine polarization of the initial response, all of the markers assessed here, including IL-2 activation, CD127 expression and anti-apoptotic markers indicate that responder cells in this transgenic system are fully fit to respond, they merely choose to do it in a different way.

The key evidence that cytokine program can be influenced by the selected TCR $\alpha \beta$ sequence itself came with the observation that by transgenic expression of a Th2 derived receptor, we produced mice that are 'Th1averse, even in the face of the most powerful possible stimulus to reverse this; despite showing strong proliferation in response to peptide, as would be expected, considerably higher than wild-type mice, there is no
IFNY or IL-17 response. Rather, the TCR transgenic mice make a strong Th2 response, not seen at all in the littermate controls. Why should this be the case? We speculate that it is an evolutionary failsafe to ensure pathogen-appropriateness of the response. In experimental immunology, we tend to work with reductionist systems where we can examine polarized Th1, Th2 or Th17 responses, unimpeded by other influences. However, in the natural host response to infection there will be many competing influences; thus, Th2 responses have presumably evolved to provide protection against parasitic infestation, yet in many parts of the world facing a major parasite burden, there is also a high level of infection with $M$. tuberculosis, itself providing a concomitant drive to Th1 and Th17 immunity [62]. Indeed, we have previously described another clinical example of this type in respect to the co-existence in the lung of sarcoidosis, which is associated with strong Th1 responses, and Cryptococcus neoformans, for which Th2 immunity is critical [63]. In complex settings, being able to avoid potentially dangerous reprogramming from pathogen-driven, cytokine milieu and promoting an appropriate effector response, is vital.

Cells with lower affinity TCRs adopt a Th2 phenotype when primed in the absence of competition from cells with higher affinity receptors [64]. Evidence that the Th2-derived TCR used in these studies are of low affinity comes from molecular modeling studies done in collaboration with Yvonne Jones' laboratory [20]. In the present study, we were able to confirm those predictions using direct tetramer binding studies. We show here that while WT littermate primed cells respond to plate-bound tetramer by making IFN $\gamma, \mathrm{TCR} \alpha \beta \mathrm{Tg}$ cells respond by making Th2 cytokines, but no IFN $\gamma$. This further emphasizes the fact that the property is purely one of the interaction between pMHC and TCR, uninfluenced by other contributory differences of co- 


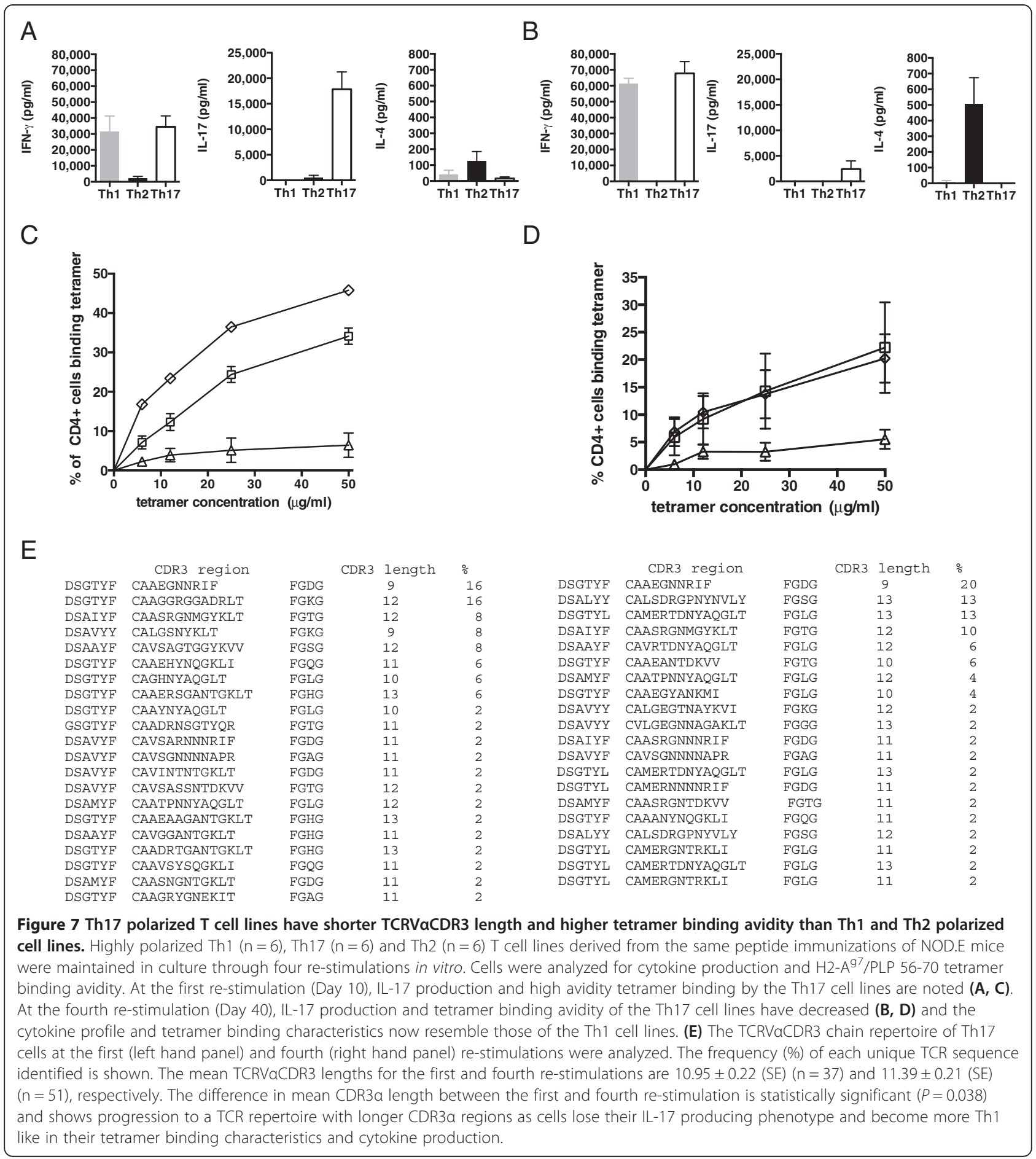

stimulatory molecules. However, despite the fact that both cell populations can be activated by tetramers, binding to the transgenic $\mathrm{T}$ cells is sufficiently low as to be undetectable. The tetramer binding studies, taken in conjunction with the preferential TCR selection described by us in polarized lines, predict that the preference for TCR avidity will be Th17 > Th1 > Th2.

\section{Conclusion}

We propose an additional and previously undefined mechanism for ensuring the cytokine appropriateness of CD4 immunity. TCR preferentially selected under Th2 conditions tended to use elongated CDR3 $\alpha$ loops and when expressed in transgenics, skewed responses away from secretion of IFN $\gamma$, favoring Th2 cytokines. 
Focusing on the $\mathrm{T}$ cell repertoire in antigen specific adaptive immunity can bring with it information not just about pMHC specificity, but also about the qualitative nature of the appropriate cytokine response.

\section{Methods}

\section{Ethics statement}

The work described in this manuscript was covered by a Home Office Project License and approved by the Imperial College Ethical Review Process.

\section{Mice}

To generate mice expressing an anti-PLP56-70/ $\mathrm{H} 2-\mathrm{Ag}^{7}$ TCR $\alpha$ chain with the elongated CDR $3 \alpha$ region, rearranged TRAV17J50 segments amplified from NOD.E genomic DNA and cDNA derived from a Th2 NOD.E T cell line against PLP56-70 and containing the CDR3 region (CALEGIASSSFSKLVF) were subcloned into pTalphaCass [65] (Figure 2A). Mice expressing a Th1 NOD.E T cell line derived anti-PLP56-70/H2- $\mathrm{Ag}^{7} \mathrm{TCR} \alpha$ chain (TRAV10/J58) with a shorter CDR3 region (CAASREGTGSKLSF) were also generated (Figure 2B). To generate mice expressing the anti-PLP56-70/H2- $\mathrm{Ag}^{7} \mathrm{TCR} \beta$ chain that pairs with the Th2 line-derived TCR $\alpha$ chain, rearranged TCRBV31J2-3 (CAWSLGGGAETLYF) segments amplified from NOD.E genomic DNA were cloned into pTbetaCass (Figure 2C). (C57BL/6xCBA) $\mathrm{F}_{2}$ oocytes were microinjected and TCRpositive founders identified by PCR and Southern. Two $\mathrm{TCR} \alpha$ chain transgenic lines with elongated CDR3 regions (called TCRAV17J50elongatedCDR3-line 20 and TCRAV 17J50elongatedCDR3-line 34) and one TCR $\alpha$ chain transgenic line with a short CDR3 region (called TRAV10 J58shortCDR3-line30) are described here. All transgenic lines underwent at least five generations of backcrossing to NOD.E mice [66]. One TCR $\beta$ chain transgenic line is described here in detail, and termed the TCRBV31J2-3 line. The TCR $\beta$ transgenic line was crossed with the TCR $\alpha$ transgenic line 20 to make a TCR $\alpha \beta$ transgenic line expressing the elongated TCR $\alpha$ CDR3 and its partner TCR $\beta C D R 3$ backcrossed onto a NOD.E background.

\section{Immunization and T cell proliferation assays}

PLP56 to 70, DYEYLINVIHAFQYV, was used for priming $T$ cell responses and the substituted analog carrying lysine for tyrosine at positions 57 and 59 for in vitro restimulation of cells [67] (Biosynthesis Inc, Lewisville, Texas, USA). The substituted analog is necessary for in vitro studies as the original sequence is poorly soluble and cytotoxic. The altered peptide retains the ability when used in vivo to trigger the expected EAE phenotype [67]. Mice were immunized with $25 \mu \mathrm{g}$ peptide in CFA or IFA (SigmaAldrich, Gillingham, Dorset, UK) in the footpad or flank. At Day 10 (unless otherwise stated) draining lymph nodes (DLN) and spleen were removed and cell suspensions were prepared in HL-1 medium (Lonza, Basel, Switzerland). Cells were cultured in triplicate in 96-well plates in the presence of peptide for three days. $\left[{ }^{3} \mathrm{H}\right]$ Thymidine was added $18 \mathrm{~h}$ before termination, and cultures were harvested (MACH III M Harvester 96) for beta scintillation counting (Wallac 1450 Microbeta TRILUX).

\section{T cell lines}

T cell lines from immunized LNC and spleen were initially set up in the presence of $25 \mu \mathrm{g} / \mathrm{ml}$ PLP peptide. To generate Th1 lines, cells were cultured in medium containing IL-2 (10 IU/ml) (National Institutes of Health, Bethesda, MD, USA), $10 \mathrm{ng} / \mathrm{ml}$ of IL-12 (R\&D systems, USA) and $10 \mu \mathrm{g} / \mathrm{ml}$ anti-IL-4 (National Institutes of Health, USA). To generate Th2 lines, cells were cultured in medium containing IL-2 (10 IU/ml) (National Institutes of Health, USA), $10 \mathrm{ng} / \mathrm{ml}$ of IL-4 (R\&D systems, Minneapolis, Minnesota, USA) and $10 \mu \mathrm{g} / \mathrm{ml}$ of anti-IFNY (Life Technologies Ltd, Paisley, UK). For Th17 lines, cells were ini-

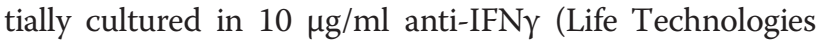
Ltd, Paisley, UK), $10 \mu \mathrm{g} / \mathrm{ml}$ anti-IL-4 (National Institutes of Health, USA), $20 \mathrm{ng} / \mathrm{ml}$ IL-6 (R\&D Systems, USA) and
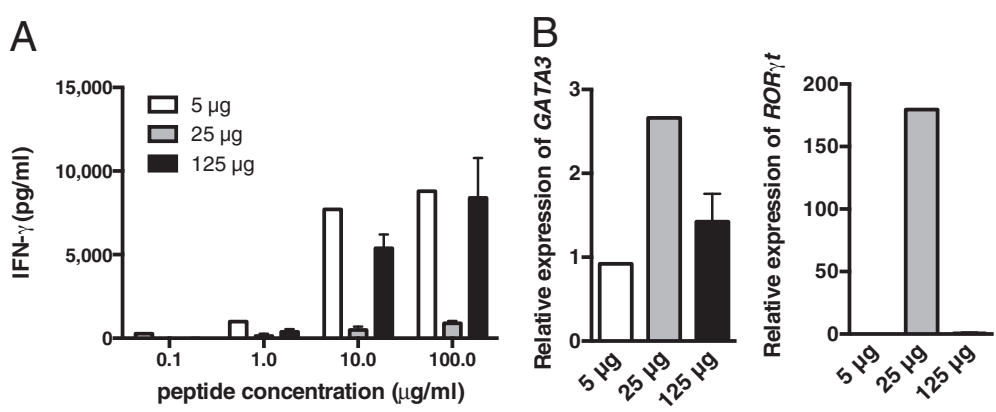

Figure 8 Impact of different in vivo peptide priming doses on ex-vivo cytokine program. Th2aß TCR transgenic mice were primed in one hind footpad with $5 \mu \mathrm{g} / \mathrm{ml}$ (open bars), $25 \mu \mathrm{g} / \mathrm{ml}$ (gray bars) or $125 \mu \mathrm{g} / \mathrm{ml}$ (black bars) PLP 56-70 peptide in CFA. At Day 10 after immunization, DLN cells were re-stimulated with peptide at $0.1,1.0,10$ or $100 \mu \mathrm{g} / \mathrm{ml}$ as indicated on the $\mathrm{x}$-axis and assayed in triplicate cultures for IFNy production by ELISA (A). RNA was prepared from primed DLN immediately ex-vivo for real-time PCR analysis of GATA-3 and RORyt transcription (B). 
$2 \mathrm{ng} / \mathrm{ml}$ TGF $\beta$ (R\&D Systems, USA) and expanded in medium containing $10 \mathrm{IU} / \mathrm{ml}$ IL-2 (National Institutes of Health, USA) and $20 \mathrm{ng} / \mathrm{ml} \mathrm{IL-23} \mathrm{(R \& D} \mathrm{Systems,} \mathrm{USA).} \mathrm{Fol-}$ lowing the addition of cytokines, cultures were incubated for an additional eight days. Cells were then resuspended in RPMI 1640 medium (Invitrogen, Life Technologies, UK) and $10 \%$ FCS, and re-stimulated with 25 to $50 \mu \mathrm{g} / \mathrm{ml}$ peptide in the presence of irradiated, syngeneic splenocytes. The 10-day cycle was repeated as required.

\section{T cell cytokine assays}

$\mathrm{T}$ cell proliferation assays of immunized lymph node cells were set up as described above. After 66 h, $50 \mu \mathrm{l}$ of supernatant was removed from each well to determine cytokine production. The IL-2, IL-4, IL-5, IL-9, IL-10, IL-13, IL-17 and IFN $\gamma$ content was measured by ELISA (R\&D Systems, UK or BD Biosciences, Franklin Lakes, New Jersey, USA). IFNy (2BScientific Ltd, Upper Heyford, UK), IL-4 (BD Biosciences, USA), IL-17 (R\&D Systems, UK). ELISPOT assays (R\&D Systems, UK) were performed using $1.2 \times$ $10^{4} \mathrm{~T}$ cells and $3 \times 10^{5}$ APCs per well with varying concentrations of peptide. Numbers of spots per well were determined using an AID ELISPOT reader (Autoimmun Diagnostika GmbH, Straßberg, Germany).

\section{Cytokine storm induction}

Mice were immunized intraperitoneally with $200 \mu \mathrm{g}$ of Staphylococcal Enterotoxin B (SEB) (Sigma Aldrich, UK) or via the footpad with phosphate-buffered saline (PBS) or $50 \mu \mathrm{g}$ of PLP peptide in CFA. Tail bleed samples were collected prior to immunization and at 2, 24 and 72 hours post immunization. Serum from tail bleed samples was used to measure IFN $\gamma$ and TNF- $\alpha$ by ELISA (R\&D Systems, UK). Thymocytes were harvested at seven days post immunization. PE-anti-CD4 (clone GK1.5, eBioscience, San Diego, California, USA) and fluorescein isothiocyanate (FITC)-anti-CD8 (clone 53 to 6.7, eBioscience, USA) were used to determine the CD4:CD8 ratio of thymocytes and to isolate $\mathrm{CD} 4$ single positive thymocytes by cell sorting on a FACS Aria II (BD Biosciences, USA).

\section{Flow cytometry}

Cell suspensions from Th1/Th2 cell lines at eight days post-re-stimulation were labeled with optimal concentrations of the following labeled monoclonals: PE-anti-CD4 (GK1.5), PE-anti-CD40L (MR1), PE-anti-ICOS (7E.17G9), PE-Rat-IgG2b isotype control, FITC-anti-CD4 (GK1.5), FITC-anti-CD69 (H1.2 F3), FITC-anti-CD3 (145-2C11), FITC-anti-CD5 (53-7.3), FITC-anti-CD54 (YN1/1.7.4), FITC-anti-CD127 (A7R34), FITC-Rat IgG2b isotype control; all from eBioscience; FITC-anti-OX40 (OX-86) from Serotec, UK; APC-anti-CD62L (MEL-14) (ImmunoTools, Friesoythe, Germany); and V500-anti-CD4
(RM4-5) (BD Biosciences, USA). Data were collected on FACSCalibur (BD Biosciences, USA) and analyzed with CellQuest software (BD Biosciences, USA) and FlowJo software (Tree Star, Inc., Ashland, Oregon, USA).

\section{TCR spectratyping}

Repertoire analyses were performed using a protocol modified from Pannetier et al. [68]. Total RNA was isolated from cell suspensions (Stratagene, Santa Clara, California, USA) followed by cDNA synthesis using SuperScript III (Invitrogen, Life Technologies). For each cDNA, PCR reactions were performed using $\mathrm{V} \beta$ primers (Milner et al., [64]) and a common 6-carboxyfluroresceinamino-hexy (6-FAM) C $\beta$ primer (6FAM-CTTGGGTGGA GTCACATTTCTC). The PCR products were analyzed on an ABI 3100 Prism Genetic Analyzer (Life Technologies,

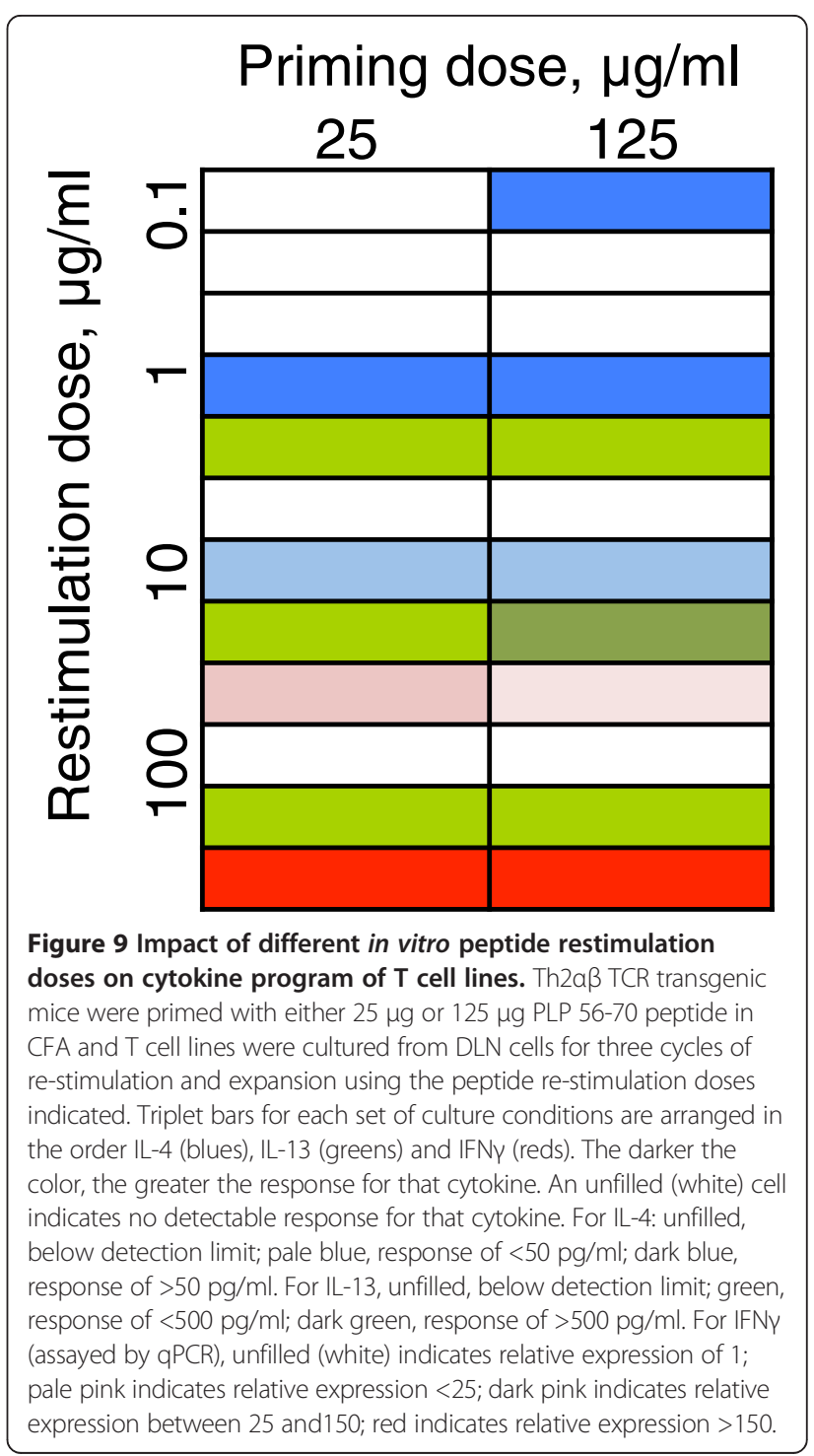




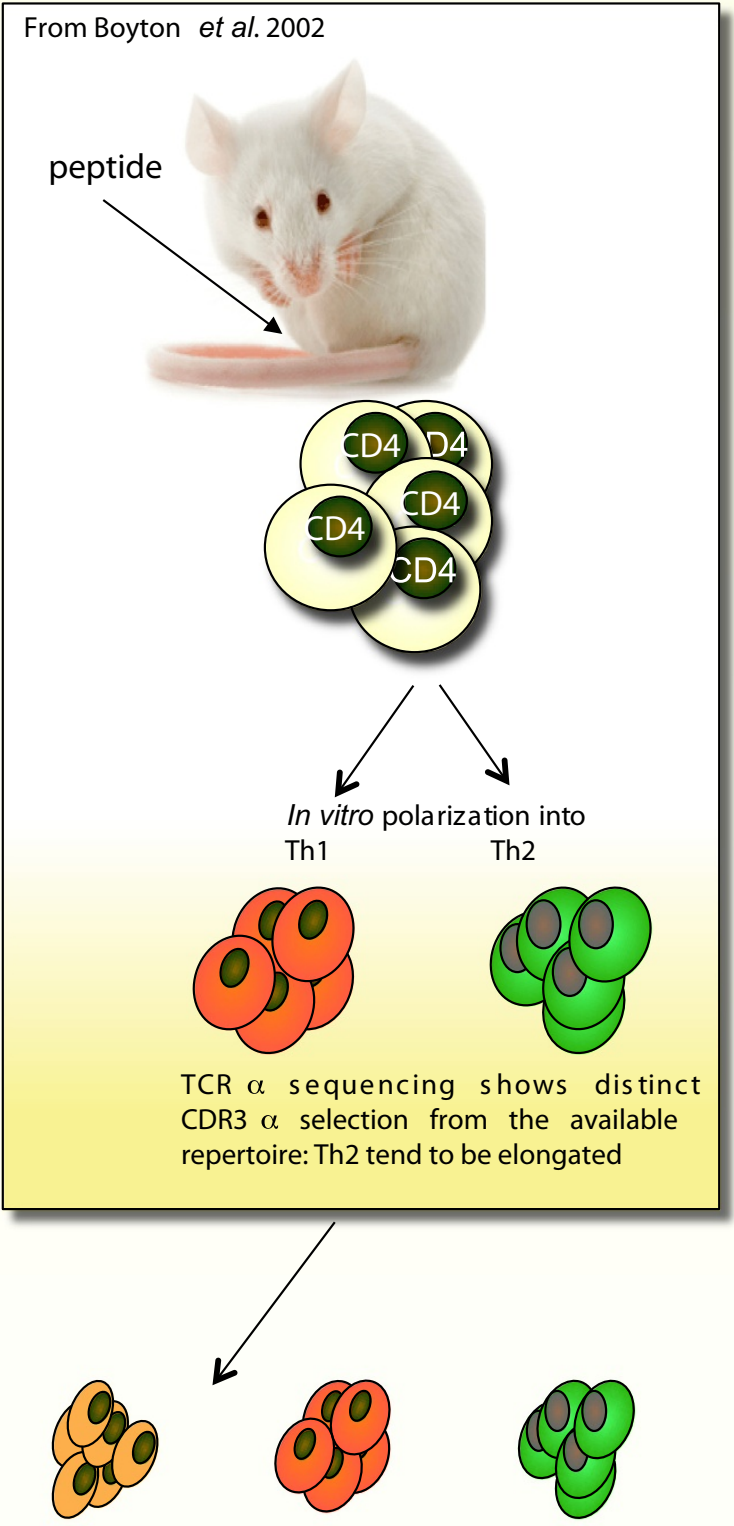

Table 1, 2, 3. CD4 T cell lines selected against the same PMHC under Th1, Th2 and Th17 polarizing conditions evolve the expansion of highly distinct, dominant TCR $\alpha$ usage. CDR3 length for Th2 $>$ Th1 $>$ Th17

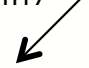

Figure 1. Th1, Th2 and Th17 polarized T cell lines have distinct cytokine profiles. Th1 and Th2 cells have different expression of costimulatory molecules (Th1>Th2 for OX40, ICAM-1, CD5, and CD40L; Th2>Th1 for ICOS) which supports the hypothesis that they interact at differing avidities
Additional File 3. Lack of support for an alternative model whereby Th2 polarization is a stochastic outcome of thymocyte depletion following a peptide-induced cytokine storm: no evidence of cytokine storm or thymocyte depletion.

Th2 derived TCR $\alpha$ transgenic with elongated CDR3 region made (construct strategy - Figure 2)
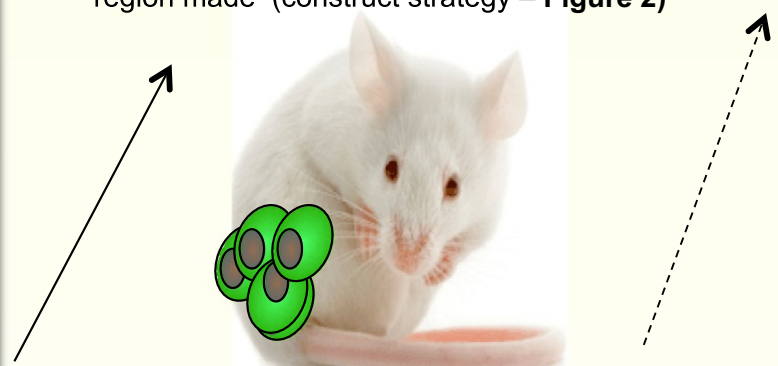

Figures 3. TCR transgenics with elongated CDR3 $\alpha$ show impaired IFN $\gamma$ responses and select a preferred TCR $\beta$ partner chain. Figure 4. Restimulation in vitro shows progressive focusing of favored TCRV $\beta$ usage correlating with the adoption of a Th2 cell phenotype (IL-4, IL-5, IL-13 and no IFN $\gamma$ plus GATA-3 transcription progressively up-regulated )

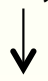

Figure 5 TCR transgenic with elongated CDR3 $\alpha$ and $\beta$ partner chains -TCR $\alpha \beta$ : primed with IFA make enhanced $T$ cell responses to peptide and Th2 cytokines (IL-4, 5, 9, 10, 13), but no IFN $\gamma$ or IL-17.

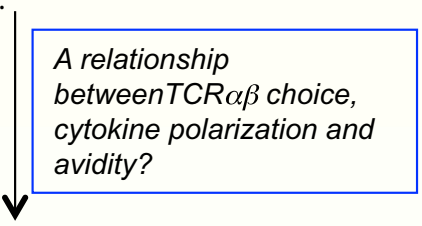

Figure 6 and 7. Th2 derived TCR $\alpha \beta$ has low avidity. Tetramer binding studies of cells from Th1/Th2/Th17 polarized T cell lines and TCR $\alpha /$ TCR $\alpha \beta$ transgenics/non-transgenic controls: while either Th2 polarized lines or cells from Th2 derived -TCR $\alpha \beta$ transgenics respond by making cytokine, binding studies indicate an avidity spectrum Th17 $>$ Th1 $1>>$ Th2.

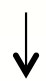

Figure 8 and 9. While transgenic expression of a Th2-derived, 'elongated' TCR-CDR3 $\alpha$ and the TCR $\alpha \beta$ pair, clearly generated a program shifted away from Th1 immunity and with low binding avidity, cytokine-skewing could be over-ridden by altering peptide priming/challenge dose.

Figure 10 Schematic illustrating the flow of experiments used here to test the hypothesis that elongated TCR alpha chain complementarity-determining region 3 favors a Th2-skewed CD4 phenotype. 
USA) using Gene Mapper ID Software version 3.2 (Life Technologies, USA).

\section{TCR subcloning and sequencing}

TCR $\alpha$ and TCR $\beta$ transcripts were amplified from cDNA prepared from bulk $\mathrm{T}$ cell lines (as described in the text) by nested PCR as described [69] and ligated into the pCR2.1 TA cloning vector, following transformation into E. coli, individual colonies were sequenced using M13 primers (Cambridge Biosciences, Cambridge, UK) by direct sequencing of purified PCR products. This was carried out using the Big Dye Terminator v1.1 Cycle Sequencing Kit and sequences, analyzed on an Applied Biosystems 3130x1 DNA Analyzer. TCR sequences and CDR3 region lengths were identified according to the International Immunogenetics Information System (IMGT) [70].

\section{Antigen specific repertoire analysis}

Single cells with a $\mathrm{CD} 4^{+} \mathrm{CD} 69^{+}$phenotype were sorted for repertoire analysis with a BD FACS Aria II and BD FACSDiva software (BD Biosciences, USA) and RNA extracted from the sorted populations.

\section{Class II tetramer binding}

Tetramer binding was performed in RPMI/FCS and the appropriate concentration of tetramer. $\mathrm{H} 2-\mathrm{Ag}^{7}$ tetramers loaded with PLP56-70 or irrelevant, CLIP103-117 peptide (PVSKMRMATPLLMQA) were used (provided by the NIH Tetramer Facility, Emory University, Atlanta, GA, USA). Cells were incubated with tetramer for $3 \mathrm{~h}$ at $37^{\circ} \mathrm{C}$ before staining with FITC-anti-CD4 (GK1.5, eBioscience, USA) and analyzing by FACS. For experiments with naïve $\mathrm{T}$ cells, $\mathrm{CD} 4^{+} \mathrm{T}$ cells were isolated from whole splenocyte cell suspensions by labelling with CD4 (L3T4) Microbeads (Miltenyi Biotec, Bergisch Gladbach, Germany) and positively selecting through an autoMACS ${ }^{\text {mi }}$ Separator (Miltenyi Biotec, Germany). For plate-bound tetramer assays, wells of high-binding plates (Corning, Corning, New York, USA) were incubated with $10 \mu \mathrm{g} / \mathrm{ml}$ tetramer overnight. Wells were blocked with $200 \mu \mathrm{l}$ medium for $1 \mathrm{~h}$ at $37^{\circ} \mathrm{C}$. A total of $5 \times 10^{4} \mathrm{~T}$ cells/well and $1 \mu \mathrm{g} / \mathrm{ml}$ of soluble anti-CD28 (clone 37.51, eBioscience, USA) were incubated for $48 \mathrm{~h}$ and supernatant collected for ELISA.

\section{Real-time PCR analysis}

RNA samples were prepared using Absolutely RNA ${ }^{\circ}$ Microprep or Nanoprep spin columns (Stratagene, USA) and cDNA synthesized from 500 ng RNA using SuperScript III reverse transcriptase (Invitrogen, Life Technologies, UK). Real-time PCR reactions were run in triplicate and CT values obtained using a MX3000P real-time PCR machine (Stratagene, USA). Variance in the amount of RNA between samples was controlled for by normalizing to 18S. Because of differences in amplification efficiencies between primer sets, relative levels of gene expression between samples were calculated by using efficiency curves to convert $\mathrm{CT}$ values to numerical values before normalizing each gene of interest value with respect to the $18 \mathrm{~S}$ value for the same sample. The sample with the lowest level of gene expression was assigned a value of 1 . Levels of gene expression in all other samples were expressed as a value relative to 1 . Gata3, Tbet, IFN $\gamma, B c l-x l$, GAPDH and $18 S$ PCR primers, TaqMan MGB probes (FAM dye labeled), as well as TaqMan Universal PCR Master Mix, were purchased from Applied Biosystems (Applied Biosystems-Assays-on-Demand Gene Expression Assay) and $R O R y t$ primers were purchased from Sigma-Aldrich (sense primer:5' GTCTGCAAGTCCTTCCGAGAG, antisense primer:5' ATCTCCCACATTGACTTCCTCTG, FAM labeled probe:5' [6FAM]CTGCGACTGGAGGACCTTCT ACGGC[TAM]).

\section{Additional files}

Additional file 1: Intracellular cytokine staining for antigen specific T cell lines. A representative example of intracellular cytokine staining for antigen specific T cell lines grown in (A) Th1 $(n=6)$ and $(\mathbf{B})$ Th17 $(n=6)$ culture media. Cell lines were grown through one re-stimulation in polarizing cell culture medium before intracellular cytokine staining with FITC-conjugated IL-17 and PE-conjugated IFNy antibodies. Note that IFNy producing cells readily differentiate within Th17 cultures, notwithstanding clear-cut overall differences in preferential TCR usage (Tables 1 and 3) and binding avidity (Figures 6 and 7).

Additional file 2: No bias in the TCR $\beta$ chain repertoire of naïve TCRVa chain transgenics at baseline or in a primary response in a DLN at Day 10 post-immunization as demonstrated by spectratype analysis. TCR $\beta$ chain repertoire by spectratype analysis of $(\mathbf{A})$ naïve TCRa transgenic and littermate control splenocytes and (B) primed DLNs at Day 10 post immunization with PLP 56 to 70 in CFA. V region specific primers were used in combination with a FAM labeled constant region primer to amplify TCR $\beta$ chain sequences from T cell CDNA templates. Data shown are representative of experiments carried out with 10 TCRa transgenic and 10 littermate controls and three independently performed experiments.

Additional file 3: No difference in T-bet transcription between TCRa $\beta$ transgenic and littermate control cell lines. TCRa $\beta$ transgenic cell lines (black bars) $(n=3)$ and littermate control lines (white bars) $(n=5)$ were established from primed DLN cells from mice primed 10 days earlier with PLP56 to 70/CFA and re-stimulated every 10 days through to four cycles in the absence of exogenous polarization. At each re-stimulation the relative expression of T-bet was determined. Error bars indicate SE.

Additional file 4: Figure S5. TCRaß transgenics show strong functional T cell activation and absence of an enhanced apoptotic program. TCRVaß transgenic $(n=4)$ and littermate control $(n=5)$ mice were primed with PLP56 to 70 on Day 0 (footpad, CFA) and Day 28 (flank, IFA). DLN and splenocytes were harvested at Day 10, Day 28 and Day 32. At the Day 32, CD4 ${ }^{+} \mathrm{T}$ cells were analyzed for expression of (A) the pro-survival factor BClxl by real time PCR (Day 32) and (B) CD127 (Day 28), and (C) CD62L (Day 28) by flow cytometry. Statistical significance between groups was determined using an unpaired t test. Error bars indicate SE

Additional file 5: Peptide priming of TCRVa, TCRVa $\beta$ transgenics or littermate controls does not result in a systemic cytokine storm or 
reduced thymocyte numbers. (A) Littermate controls, TCRVa and TCRVa $\beta$ transgencis were immunized with $200 \mu \mathrm{g}$ SEB (striped bars) (littermate controls, $n=5$; TCRVa, $n=9$; TCRVa $\beta, n=9$ ), PBS/CFA (white bars) (littermate controls, $n=4$; TCRVa, $n=4$; TCRVa $\beta, n=4$ ), or $50 \mu \mathrm{g}$ PLP/CFA (black bars) (littermate controls, $n=4 ; T C R V a, n=4 ; T C R V a \beta$, $n=4$ ). (B) Serum samples were collected at time points $0,2,24$ and 72 hours from mice injected with SEB (striped bars), PBS/CFA (white bars) or $50 \mu \mathrm{g}$ PLP/CFA (black bars) and IFNY (top row) and TNF-a (middle row) levels measured by ELISA. On Day 7, total thymocyte counts and CD4/CD8 thymocyte ratios were determined (bottom row). CD4 single positive thymocytes were isolated by cell sorting and the CDR3 $\beta$ repertoire of (C) littermate controls and (D) TCRVa transgenic mice immunized with PLP/CFA determined by TCR subcloning and sequencing.

\section{Abbreviations}

APC: Antigen presenting cell; BCl2: B-cell lymphoma 2; BCLxL: B-cell lymphoma-extra large; CDNA: Complementary DNA; CDR3: Complementarity determining region 3; CFA: Complete Freund's adjuvant; CTLA-4: Cytotoxic T-lymphocyte antigen 4; DC: Dendritic cell; EAE: Experimental autoimmune encephalomyelitis; ELISA: Enzyme-linked immunosorbent assay; FACS: Fluorescence activated cell sorter; FITC: Fluorescein isothiocyanate; ICAM-1: Intercellular adhesion molecule-1; ICOS: Inducible T-cell co-stimulator; IFA: Incomplete Freund's adjuvant; IFNY: Interferon gamma; IL-2: 4, 9, 10, 12, 13, 17, 18, 23, Interleukin-2, 4, 9, 10, 12, 13, 17, 18, 23; LCMV: Lymphochoriomeningitis virus; LNC: Lymph node cells; MHC: Major histocompatibility complex; NOD.E: Non-obese diabetic, H2-E transgenic; PCR: Polymerase chain reaction; PLP: Proteolipoprotein; PMHC: peptide/major histocompatibility complex; SEA: Schistosome egg antigen; SEB: Staphylococcal enterotoxin B; TCR: T cell receptor; TGF $\beta$ : Transforming growth factor beta; Th1: 2, 17, T helper 1, 2, 17; TLR: Toll-like receptor; TNFa: Tumor necrosis factor alpha.

\section{Competing interests}

The authors declare that they have no competing interests.

\section{Authors' contributions}

$C R$ acquired the data, analyzed and interpreted the data, and Drafted or revised the manuscript. DC, ER, KQ, DK and JL-H acquired the data. DA analyzed and interpreted the data, and drafted or revised the manuscript. RB was responsible for conception and design of the study, acquisition of data, analysis and interpretation of data, and drafting or revising the manuscript. All authors read and approved the final manuscript.

\section{Authors' information}

$\mathrm{CR}$ and $\mathrm{DC}$ are post-doctoral research associates. ER and $\mathrm{KQ}$ are PhD students. DK is a MSc student. JLH is a DNA sequencing Facility Manager. DA is a Professor of Immunology. RB is the Principal Investigator and Head of the Lung Immunology Group.

\section{Acknowledgments}

We thank D. Mathis and C. Benoist (Harvard Medical School, Boston, MA, USA) for supplying pTalphaCass and pTbetaCass constructs; Zoe Webster (MRC CSC, Imperial College London), Robert Summer and Colin Hetherington (Nuffield Department of Medicine, Oxford University) for pronuclear injections. We thank the NIH Tetramer Core Facility (Emory University, Atlanta, GA, USA) for providing tetramer reagents. We thank Anna Ettorre and the NIHR BRC Imaging and FACS Sorting Facility, Hammersmith Campus, Imperial College London for help with FACS sorting. We thank M. Green, S. Durham and M. Dallman for their advice and support. The Medical Research Council UK (G108/495 MRC Clinician Scientist Fellowship to RB), and the Welton Foundation UK (PC3015 and P14475 to RB) supported this work. The funders had no role in study design, data collection and analysis, decision to publish, or preparation of the manuscript.

\section{Author details}

'Lung Immunology Group, Infectious Diseases and Immunity, Department of Medicine, Imperial College, Hammersmith Hospital, Du Cane Road, London W12 ONN, UK. ${ }^{2}$ Molecular Biology Laboratories, Natural History Museum, Cromwell Road, London SW7 5BD, UK.
Received: 24 February 2014 Accepted: 4 April 2014

Published: 9 May 2014

\section{References}

1. Wan YY, Flavell RA: How diverse - CD4 effector T cells and their functions. J Mol Cell Biol 2009, 1:20-36.

2. Zhou L, Chong MM, Littman DR: Plasticity of CD4+ T cell lineage differentiation. Immunity 2009, 30:646-655.

3. Graham MB, Braciale VL, Braciale TJ: Influenza virus specific CD4 ${ }^{+}$T helper type $2 \mathrm{~T}$ lymphocytes do not promote recovery from experimental virus infection. J Exp Med 1994, 180:1273-1282.

4. Robinson DS, Hamid Q, Ying S, Tsicopoulos A, Barkans J, Bentley AM, Corrigan C, Durham SR, Kay AB: Predominant TH2-like bronchoalveolar T-lymphocyte population in atopic asthma. N Engl J Med 1992, 326:298-304.

5. Trinchieri G: Interleukin-12 and the regulation of innate resistance and adaptive immunity. Nat Rev Immunol 2003, 3:133-146.

6. MacDonald AS, Maizels RM: Alarming dendritic cells for Th2 induction. J Exp Med 2008, 205:13-17.

7. Cervi L, MacDonald AS, Kane C, Dzierszinski F, Pearce EJ: Cutting edge: dendritic cells copulsed with microbial and helminth antigens undergo modified maturation, segregate the antigens to distinct intracellular compartments, and concurrently induce microbe-specific Th1 and helminth-specific Th2 responses. J Immunol 2004, 172:2016-2020.

8. Lutz MB, Schuler G: Immature, semi-mature and fully mature dendritic cells: which signals induce tolerance or immunity? Trends Immunol 2002 23:445-449

9. lezzi $G$, Scotet $E$, Scheidegger $D$, Lanzavecchia $A$ : The interplay between the duration of TCR and cytokine signaling determines T cell polarization. Eur J Immunol 1999, 29:4092-4101.

10. Tao X, Constant S, Jorritsma P, Bottomly K: Strength of TCR signal determines the costimulatory requirements for Th1 and Th2 CD4+ T cell differentiation. J Immunol 1997, 159:5956-5963.

11. Lanzavecchia A, lezzi G, Viola A: From TCR engagement to T cell activation: a kinetic view of T cell behavior. Cell 1999, 96:1-4.

12. Constant $S$, Pfeiffer $C$, Woodard A, Pasqualini T, Bottomly K: Extent of $T$ cell receptor ligation can determine the functional differentiation of naïve CD4 ${ }^{+}$T cells. J Exp Med 1995, 182:1591-1596.

13. Leitenberg D, Boutin Y, Constant S, Bottomly K: CD4 regulation of TCR signaling and $\mathrm{T}$ cell differentiation following stimulation with peptides of different affinities for the TCR. J Immunol 1998, 161:1194-1203.

14. Ruedl C, Bachmann MF, Kopf M: The antigen dose determines Thelper subset development by regulation of CD40 ligand. Eur J Immunol 2000, 30:2056-2064.

15. Sloan-Lancaster J, Steinberg TH, Allen PM: Selective loss of the calcium ion signaling pathway in T cells maturing toward a T helper 2 phenotype. J Immunol 1997, 159:1160-1168.

16. Das MP, Nicholson LB, Greer JM, Kuchroo VK: Autopathogenic T helper cell type 1 (Th1) and protective Th2 clones differ in their recognition of the autoantigenic peptide of myelin proteolipid protein. J Exp Med 1997, 186:867-876.

17. Busch DH, Pamer EG: T cell affinity maturation by selective expansion during infection. J Exp Med 1999, 189:701-710.

18. Fassò M, Anandasabapathy N, Crawford F, Kappler J, Fathman CG, Ridgway WM: T cell receptor (TCR)-mediated repertoire selection and loss of TCR vbeta diversity during the initiation of a CD4(+) T cell response in vivo. J Exp Med 2000, 192:1719-1713.

19. McHeyzer-Williams MG, Davis MM: Antigen-specific development of primary and memory T cells in vivo. Science 1995, 268:106-111.

20. Boyton RJ, Zaccai N, Jones EY, Altmann DM: CD4 T cells selected by antigen under Th2 polarizing conditions favor an elongated TCR alpha chain complementarity-determining region 3. J Immunol 2002, 168:1018-1027.

21. Hsieh CS, Macatonia SE, O'Garra A, Murphy KM: T cell genetic background determines default $\mathrm{T}$ helper phenotype development in vitro. J Exp Med 1995, 181:713-721.

22. Boyton RJ, Altmann DM: Is selection for TCR affinity a factor in cytokine polarization? Trends Immunol 2002, 23:526-529.

23. Ansel KM, Lee DU, Rao A: An epigenetic view of helper T cell differentiation. Nat Immunol 2003, 4:616-623. 
24. Bending D, De La Peña H, Veldhoen M, Phillips JM, Uyttenhove C, Stockinger B, Cooke A: Highly purified Th17 cells from BDC2.5NOD mice convert into Th1-like cells in NOD/SCID recipient mice. J Clin Invest 2009, 119:565-572.

25. Ivanov II, McKenzie BS, Zhou L, Tadokoro CE, Lepelley A, Lafaille JJ, Littman DR: The orphan nuclear receptor RORgammaT directs the differentiation program of proinflammatory IL-17+ Thelper cells. Cell 2006, 126:1121-1133.

26. Lee YK, Turner H, Maynard CL, Oliver JR, Chen D, Elson CO, Weaver CT: Late developmental plasticity in the T helper 17 lineage. Immunity 2009, 30:92-107.

27. Luger D, Silver PB, Tang J, Cua D, Chen Z, Iwakura Y, Caspi RR: Either a Th17 or a Th1 effector response can drive autoimmunity: conditions of disease induction affect dominant effector category. J Exp Med 2008, 205:799-810.

28. Tesciuba AG, Subudhi S, Rother RP, Faas SJ, Frantz AM, Elliot D, Sperling Al: Inducible costimulator regulates Th2-mediated inflammation, but not Th2 differentiation, in a model of allergic airway disease. J Immunol 2001, 167:1996-2003.

29. Mandl JN, Monteiro JP, Vrisekoop N, Germain RN: T cell-positive selection uses self-ligand binding strength to optimize repertoire recognition of foreign antigens. Immunity 2013, 38:263-274.

30. Su SB, Silver PB, Grajewski RS, Agarwal RK, Tang J, Chan CC, Caspi RR: Essential role of the MyD88 pathway, but nonessential roles of TLRs 2, 4, and 9, in the adjuvant effect promoting Th1-mediated autoimmunity. J Immunol 2005, 175:6303-6310.

31. Jenner RG, Townsend MJ, Jackson I, Sun K, Bouwman RD, Young RA, Lord GM: The transcription factors T-bet and GATA-3 control alternative pathways of T-cell differentiation through a shared set of target genes. Proc Natl Acad Sci U S A 2009, 106:17876-17881.

32. Kemp KL, Levin SD, Bryce PJ, Stein PL: Lck mediates Th2 differentiation through effects on T-bet and GATA-3. J Immunol 2010, 184:4178-4184.

33. Gett AV, Sallusto F, Lanzavecchia A, Geginat J: T cell fitness determined by signal strength. Nat Immunol 2003, 4:355-360.

34. Hataye J, Moon JJ, Khoruts A, Reilly C, Jenkins MK: Naive and memory CD4+ T cell survival controlled by clonal abundance. Science 2006, 312:114-116.

35. Whitmire JK, Benning N, Eam B, Whitton JL: Increasing the CD4+ T cell precursor frequency leads to competition for IFN-gamma thereby degrading memory cell quantity and quality. J Immuno/ 2008, 180:6777-6785.

36. Vander Heiden MG, Chandel NS, Williamson EK, Schumacker PT, Thompson $\mathrm{CB}$ : $\mathrm{BCl}-\mathrm{xL}$ regulates the membrane potential and volume homeostasis of mitochondria. Cell 1997, 91:627-637.

37. Vander Heiden MG, Thompson CB: BCl-2 proteins: regulators of apoptosis or of mitochondrial homeostasis? Nat Cell Biol 1999, 1:E209-E216.

38. Rathmell JC, Thompson CB: Pathways of apoptosis in lymphocyte development, homeostasis, and disease. Cell 2002, 109:S97-S107.

39. Broome HE, Dargan CM, Krajewski S, Reed JC: Expression of Bcl-2, BCl-x, and Bax after T cell activation and IL-2 withdrawal. J Immunol 1995, 155:2311-2317.

40. Faulkner L, Cooper A, Fantino C, Altmann DM, Sriskandan S: The mechanism of superantigen-mediated toxic shock: not a simple Th1 cytokine storm. J Immunol 2005, 175:6870-6877.

41. Hosken NA, Shibuya K, Heath AW, Murphy KM, O'Garra A: The effect of antigen dose on CD4+ T helper cell phenotype development in a $\mathrm{T}$ cell receptor-alpha beta-transgenic model. J Exp Med 1995, 182:1579-1584.

42. Rudolph MG, Stanfield RL, Wilson IA: How TCRs bind MHCs, peptides, and coreceptors. Annu Rev Immunol 2006, 24:419-466.

43. Deng L, Langley RJ, Wang Q, Topalian SL, Mariuzza RA: Structural insights into the editing of germ-line-encoded interactions between T-cell receptor and MHC class II by Va CDR3. Proc Natl Acad Sci U S A 2012, 109:14960-14965.

44. Waldner H, Whitters MJ, Sobel RA, Collins M, Kuchroo VK: Fulminant spontaneous autoimmunity of the central nervous system in mice transgenic for the myelin proteolipid protein-specific T cell receptor. Proc Natl Acad Sci U S A 2000, 97:3412-3417.

45. Candon S, McHugh RS, Foucras G, Natarajan K, Shevach EM, Margulies DH: Spontaneous organ-specific Th2-mediated autoimmunity in TCR transgenic mice. J Immunol 2004, 172:2917-2924.

46. Steinman RM, Hemmi H: Dendritic cells: translating innate to adaptive immunity. Curr Top Microbiol Immunol 2006, 311:17-58.

47. Leung MW, Shen S, Lafaille JJ: TCR-dependent differentiation of thymic Foxp3+ cells is limited to small clonal sizes. J Exp Med 2009, 206:2121-2130
48. DiPaolo RJ, Shevach EM: CD4+ T-cell development in a mouse expressing a transgenic TCR derived from a Treg. Eur J Immunol 2009, 39:234-240.

49. Marsland BJ, Kopf M: T-cell fate and function: PKC-theta and beyond. Trends Immunol 2008, 29:179-185.

50. Kedzierska K, La Gruta NL, Stambas J, Turner SJ, Doherty PC: Tracking phenotypically and functionally distinct $T$ cell subsets via $T$ cell repertoire diversity. Mol Immunol 2008, 45:607-618.

51. Malherbe L, Hausl C, Teyton L, McHeyzer-Williams MG: Clonal selection of helper T cells is determined by an affinity threshold with no further skewing of TCR binding properties. Immunity 2004, 21:669-679.

52. Williams MA, Ravkov EV, Bevan MJ: Rapid culling of the CD4+ T cell repertoire in the transition from effector to memory. Immunity 2008, 28:533-545.

53. Krawczyk CM, Shen H, Pearce EJ: Functional plasticity of T helper cell responses. J Immunol 2007, 178:4080-4088.

54. Garcia KC, Radu CG, Ho J, Ober RJ, Ward ES: Kinetics and thermodynamics of T cell receptor- autoantigen interactions in murine experimental autoimmune encephalomyelitis. Proc Nat Acad Sci U S A 2001, 98:6818-6823.

55. Itoh Y, Wang Z, Ishida H, Eichelberg K, Fujimoto N, Makino J, Ogasawara K, Germain RN: Decreased CD4 expression by polarized T helper 2 cells contributes to suboptimal TCR-induced phosphorylation and reduced Ca2+ signaling. Eur J Immunol 2005, 35:3187-3195.

56. Azzam HS, Grinberg A, Lui K, Shen H, Shores EW, Love PE: CD5 expression is developmentally regulated by $T$ cell receptor (TCR) signals and TCR avidity. J Exp Med 1998, 188:2301-2311.

57. Jackman RP, Balamuth F, Bottomly K: CTLA-4 differentially regulates the immunological synapse in CD4 T cell subsets. J Immunol 2009, 178:5543-5551.

58. Balamuth F, Brogdon $J$, Bottomly $\mathrm{K}$ : CD4 raft association and signaling regulate molecular clustering at the immunological synapse site. $\mathrm{J}$ Immunol 2004, 172:5887-5892.

59. Thauland TJ, Koguchi Y, Wetzel SA, Dustin ML, Parker DC: Th1 and Th2 cells form morphologically distinct immunological synapses. J Immunol 2008, 181:393-399.

60. Brogdon JL, Leitenberg D, Bottomly K: The potency of TCR signaling differentially regulates NFATc/p activity and early IL-4 transcription in naive CD4+ T cells. J Immunol 2002, 168:3825-3832.

61. Jameson SC, Masopust D: Diversity in T cell memory: an embarrassment of riches. Immunity 2009, 31:859-871.

62. Curtis MM, Way SS: Interleukin-17 in host defence against bacterial, mycobacterial and fungal pathogens. Immunology 2009, 126:177-185.

63. Boyton RJ, Altmann DM, Wright A, Kon OM: Pulmonary infection with Cryptococcus neoformans in the face of underlying sarcoidosis. Respiration 2007, 74:462-466.

64. Milner JD, Fazilleau N, McHeyzer-Williams M, Paul W: Cutting edge. Lack of high affinity competition for peptide in polyclonal CD4+ responses unmasks IL-4 production. J Immuno/ 2010, 184:6569-6573.

65. Kouskoff V, Signorelli K, Benoist C, Mathis D: Cassette vectors directing expression of $\mathrm{T}$ cell receptor genes in transgenic mice. J Immunol Methods 1995, 180:273-280.

66. Lund T, O'Reilly L, Hutchings P, Kanagawa O, Simpson E, Gravely R, Chandler $P$, Dyson J, Picard JK, Edwards A, Kioussis D, Cooke A: Prevention of insulin-dependent diabetes mellitus in non-obese diabetic mice by transgenes encoding modified I-A -chain or normal I-E -chain. Nature 1990, 345:727-729.

67. Amor S, O'Neill JK, Morris MM, Smith RM, Wraith DC, Groome N, Baker D: Encephalitogenic epitopes of myelin basic protein, proteolipid protein, myelin oligodendrocyte glycoprotein for experimental allergic encephalomyelitis induction in Biozzi $\mathrm{ABH}(\mathrm{H}-2 \mathrm{Ag} 7)$ mice share an amino acid motif. J Immunol 1996, 156:3000-3008.

68. Pannetier C, Cochet M, Darche S, Casrouge A, Zöller M, Kourilsky P: The sizes of the CDR3 hypervariable regions of the murine T-cell receptor beta chains vary as a function of the recombined germ-line segments. Proc Natl Acad Sci U S A 1993, 90:4319-4323.

69. Candeias S, Katz J, Benoist C, Mathis D, Haskins K: Islet-specific T-cell clones from nonobese diabetic mice express heterogeneous T-cell receptors. Proc Natl Acad Sci U S A 1991, 88:6167-6170.

70. IMGT/Genelnfo. [http://www.imgt.org]

doi:10.1186/1741-7007-12-32

Cite this article as: Reynolds et al:: Elongated TCR alpha chain CDR3 favors an altered CD4 cytokine profile. BMC Biology 2014 12:32. 